\title{
LODO DE ESGOTO E PRODUÇÃO DE PALMITO EM PUPUNHEIRA ${ }^{(1)}$
}

\author{
Marilene Leão Alves Bovi ${ }^{(2) \dagger}$, Gentil Godoy Júnior ${ }^{(3)}$, Eduardo Antonio \\ ${\text { Drolhe da } \text { Costa }^{(3)} \text {, Ronaldo Severiano Berton }}^{(4)}$, Sandra Heiden \\ Spiering ${ }^{(2)}$, Fernando Vinicius Armas Vega ${ }^{(5)}$, Matheus de Aguiar \\ Rodrigues Cembranelli ${ }^{(5)}$ \& Carlos Alberto Baca Maldonado ${ }^{(5)}$
}

\begin{abstract}
RESUMO
O uso agrícola do lodo de esgoto vem se mostrando como opção para reduzir impactos ambientais e poluição das águas. No entanto, há necessidade de se adequar dose e freqüência de aplicação para cada cultura. Durante 40 meses, foram avaliados, em experimento de campo instalado em Ubatuba (SP), os efeitos de doses de lodo de esgoto sobre a precocidade de colheita e a produção de palmito de pupunheira. Foram testadas quatro doses anuais de lodo, correspondentes a 0, 0,5, 1,0 e 2,0 vezes a quantidade de nitrogênio recomendada para o cultivo, sob delineamento de blocos ao acaso. A primeira aplicação foi efetuada no sulco de plantio durante a instalação do experimento (seis repetições), enquanto as demais foram realizadas anualmente, em superfície ou incorporadas nas entrelinhas da cultura (três repetições cada). Adubações complementares com cloreto de potássio e ácido bórico foram efetuadas trimestralmente, para corrigir deficiências. Utilizaram-se mudas inermes do ecótipo, com 10 meses de idade e densidade de plantio de 5.000 plantas ha-1. As respostas das plantas às doses de lodo foram avaliadas mensalmente, por meio de caracteres diretamente relacionados à precocidade de colheita e à produção de palmito. Houve resposta linear positiva de acordo com as doses empregadas para todos os caracteres avaliados. $O$ uso de lodo de esgoto no sulco de plantio antecipou a primeira colheita de palmito em mais de três meses, quando comparadas dose máxima e testemunha. Não houve diferenças significativas entre as duas formas de aplicação de lodo. O número de hastes colhidas por ano e por planta variou de 0,45 a 1,04 , de acordo com as doses
\end{abstract}

\footnotetext{
(1) Projeto parcialmente financiado pela SABESP. Recebido para publicação em agosto de 2005 e aprovado em novembro de 2006.

${ }^{(2) \dagger}$ Pesquisadora do Centro de Horticultura, Instituto Agronômico - IAC. Caixa Postal 28, CEP 13001-970 Campinas (SP). in memorian.

(3) Pesquisador da Unidade de Pesquisa e Desenvolvimento de Ubatuba, APTA. Rod. Oswaldo Cruz 5061, CEP 13680-000 Ubatuba (SP). E-mail: eduardodrolhe@aptaregional.sp.gov.br

(4) Pesquisador do Centro de Solos e Recursos Ambientais, IAC. E-mail: berton@iac.sp.gov.br

(5) Pós-graduando do Instituto Agronômico de Campinas - IAC. E-mail: cembranelli@iac.sp.gov.br; maldonado@iac.sp.gov.br
} 
aplicadas. A produção média anual de palmito variou de 0,82 a $1,65 \mathrm{t} \mathrm{ha}^{-1} \mathrm{ano}^{-1} \mathrm{e} \mathrm{de}$ 0,87 a 1,39 $\mathrm{t} \mathrm{ha}^{-1}$ ano $^{-1}$ de resíduo basal, com aumento proporcional ao das doses de lodo de esgoto. Concluiu-se então que o uso de lodo de esgoto no cultivo da pupunheira é viável e atende, em parte, às necessidades da cultura.

Termos para indexação: Bactris gasipaes, biossólido, colheita, pupunha.

\title{
SUMMARY: SEWAGE SLUDGE DOSES AND HEART-OF-PALM YIELD IN PEACH PALM
}

\begin{abstract}
Sewage sludge has been used in agriculture in many crops as an alternative to reduce environmental impacts and water pollution. Nonetheless there is a need to adjust rates and timing for each crop. Therefore, the effects of sludge application on earliness and heart-of-palm yield were studied in peach palm in a field experiment carried out in Ubatuba, $S P$, Brazil. Four annual nitrogen rates, $(0,0.5,1.0$ and 2.0 times the recommended amounts for the crop) were tested in a complete block design. The first application was incorporated at planting (6 replications), whereas the others were performed annually, as top dressing or incorporated between plant rows (3 replications). Potassium chloride and boric acid were applied as complementary fertilization every three months to correct plant deficiencies. Ten-month-old seedlings were used in a planting density of 5,000 plants ha ${ }^{-1}$. The plant response to sewage sludge doses was evaluated monthly, through traits directly correlated to peach palm yield, for 40 months. Statistical differences in response to the doses were detected for all variables. An anticipation of the harvest of over three months could be detected when the highest and lowest doses were compared. No differences resulted from the application forms. There was an increase in yield proportional to the sludge rates, varying from 0.82 to $1.65 \mathrm{tha}^{-1}$ year ${ }^{-1}$ of heart-of-palm and from 0.87 to $1.39 \mathrm{tha}^{-1}$ year $^{-1}$ of basal stem. It was concluded that sewage sludge application is suitable for peach palm and meets, partly, the fertilization needs of the crop.
\end{abstract}

Index terms: Bactris gasipaes, biosolids, harvest, heart-of-palm, pejibaye.

\section{INTRODUÇÃO}

O tratamento do esgoto doméstico gera um resíduo denominado lodo de esgoto, que, além de conter alto teor de matéria orgânica, possui quantidades apreciáveis de nutrientes, principalmente $\mathrm{N}$ e $\mathrm{P}$, podendo melhorar as propriedades físicas, químicas e biológicas do solo, ou ser utilizado como fonte de nutrientes para o crescimento das plantas (Berton et al., 1989; Serra-Wittling et al., 1996; Vieira \& Cardoso, 2003). Estima-se que, no Estado de São Paulo, a produção diária de lodo de esgoto em 2006 tinha sido de $630 \mathrm{Mg}$. Entretanto, a disposição final do lodo é problemática e o descarte desse resíduo tem sido negligenciado, representando custos de até $50 \%$ do orçamento operacional do sistema de tratamento, o que pode anular os benefícios da coleta e do tratamento dos efluentes, tornando-se novo problema ambiental (Berton, 2000; Berton \& Camargo, 2004). Dessa forma, o uso de lodo de esgoto na agricultura pode consistir numa das alternativas mais viáveis para minimizar o risco ambiental, bem como para garantir reciclagem de nutrientes que, no futuro, poderão ter aplicação restringida (Bataglia et al., 1983a).
Pesquisas recentes, efetuadas em nosso país, mostraram a potencialidade da utilização do lodo de esgoto em uma série de culturas, entre elas milho (Anjos \& Mattiazzo, 2000; Nascimento et al., 2004; Silva et al., 2006), cana-de-açúcar (Oliveira \& Mattiazzo, 2001; Silva et al., 2001), eucalipto (Trigueiro \& Guerrini, 2003; Guedes et al., 2006), feijão e soja (Nascimento et al., 2004; Vieira et al., 2005), alface (Lopes et al., 2005) e, inclusive, pupunheira (Vega, 2003; Vega et al., 2005). O cultivo dessa palmeira para produção de palmito vem aumentando consideravelmente no Brasil. Trata-se de planta precoce, porém exigente em propriedades físicas e químicas do solo, extraindo grande quantidade de nutrientes. Máxima produtividade em palmito somente é obtida com adubação balanceada (Deenik et al., 2000; Bovi et al., 2002; Molina et al., 2002; Ramos et al., 2004). No entanto, a pupunheira é cultura adequada à aplicação de lodo, visto que responde à adubação orgânica de forma mais acentuada que à química (Herrera, 1989; Yuyama, 1997; Bovi et al., 2000; Oliveira et al., 2001; Nascimento et al., 2005). Portanto, o uso de matéria orgânica, principalmente no plantio, é altamente 
recomendado para a pupunheira, embora nem sempre efetuado devido aos custos elevados e à falta de disponibilidade de adubos orgânicos. A presença de estações de tratamento de esgoto nas áreas aptas ao cultivo da pupunheira no Estado de São Paulo facilita o uso desse resíduo. No entanto, em razão da carência de pesquisas no setor, há necessidade de se adequar dose e freqüência de aplicação para a cultura.

Segundo Tsutiya (2001), há vários critérios para a escolha da taxa de aplicação de lodo de esgoto em áreas agrícolas, merecendo destaque a quantidade de nitrogênio disponível no lodo, o teor de metais acumulados no solo após a aplicação do lodo, a capacidade do lodo de neutralizar a acidez do solo, ou mesmo em função de outros nutrientes eventualmente presentes no lodo. Com base nesses e em outros critérios, observa-se grande variação nas doses empregadas em vários estudos. Valores máximos de lodo de esgoto para uso agrícola, variando de 20 a $388 \mathrm{Mg} \mathrm{ha}{ }^{-1}$ (base seca), foram encontrados na literatura (Oliveira et al., 1995; Anjos \& Mattiazzo, 2000; Oliveira \& Mattiazzo, 2001; Silva et al., 2001; Martins et al., 2005; Scavroni et al., 2005). No entanto, embora respostas positivas em crescimento e produtividade das espécies em estudo tenham sido observadas em doses elevadas, já foi comprovado que estas podem causar danos severos ao ambiente, tanto pelo acúmulo de metais pesados (Higgins, 1984; Bertoncini \& Mattiazzo, 1999; Berton, 2000; Keller et al., 2002; Molina, 2004) quanto pela contaminação do lençol freático (Burton et al., 1990; Oliveira, 1995; Vieira \& Cardoso, 2003; Molina, 2004).

O objetivo deste trabalho foi avaliar, durante um período de 40 meses, os efeitos de quatro doses de lodo de esgoto, aplicadas primeiramente no sulco de plantio e posteriormente em superfície ou incorporadas nas entrelinhas, sobre caracteres relacionados à precocidade de colheita e à produtividade da pupunheira, em cultivo visando à produção de palmito.

\section{MATERIAL E MÉTODOS}

O experimento foi instalado em campo, em julho de 2001 , em Ubatuba, $\mathrm{SP}\left(23^{\circ} 27^{\prime}\right.$ 'S e $45^{\circ} 04$ ' O, a $6 \mathrm{~m}$ de altitude). $\mathrm{O}$ clima da região é do tipo $\mathrm{Cfa}$, pela classificação de Köppen, tropical quente e úmido (Setzer, 1966), com pluviosidade anual normal de $2.841 \mathrm{~mm}$, evapotranspiração potencial normal de $992 \mathrm{~mm}$, excedente normal de $1.849 \mathrm{~mm}$, temperatura média anual de $20,8^{\circ} \mathrm{C}$ e déficit hídrico nulo.

O solo da área experimental é classificado como Neossolo Flúvico Psamítico típico álico (Embrapa, 1999), arenoso e com boa drenagem. Apresenta a seguinte composição granulométrica na profundidade de $0-15 \mathrm{~cm}$ : $100 \mathrm{~g} \mathrm{~kg}^{-1}$ de argila, $140 \mathrm{~g} \mathrm{~kg}^{-1}$ de silte, $130 \mathrm{~g} \mathrm{~kg}^{-1}$ de areia fina e $630 \mathrm{~g} \mathrm{~kg}^{-1}$ de areia grossa. Ao longo do perfil observa-se progressiva diminuição na porcentagem de areia grossa e aumento da areia fina. A porosidade total na profundidade de $0-20 \mathrm{~cm}$ é de $49,97 \%$, sendo $29,65 \%$ de macroporos e $20,32 \%$ de microporos (Jorge \& Bovi, 1994). A densidade global do solo está em torno de $1,05 \mathrm{~g} \mathrm{~cm}^{-3}$ (Vega et al., 2005). Análises químicas, efetuadas, segundo os métodos propostos por Abreu et al. (2001) e Raij \& Quaggio (2001), em amostras de solo retiradas da área experimental, evidenciaram a necessidade de calagem (Quadro 1). Esta foi feita de acordo com o método de saturação do solo por bases, como descrito por Raij (1991), de forma que elevasse a saturação teórica (V) a $60 \%$, aplicando-se em superfície, seguida de incorporação por aração e gradagem, o equivalente a $4,7 \mathrm{Mg} \mathrm{ha}^{-1}$ de calcário dolomítico. Amostras de solo foram retiradas 60 dias após a calagem, obtendo-se as características químicas expressas no quadro 1.

O lodo de esgoto foi aplicado em duas fases distintas: primeiramente na implantação da cultura, durante a operação de plantio (aplicação incorporada), com efeitos avaliados até os 16 meses da aplicação; e posteriormente na manutenção do cultivo (aplicação incorporada e em superfície), com efeitos avaliados do $17^{\circ}$ ao $40^{\circ}$ mês do início do experimento. Em todas as aplicações foi utilizado o lodo da Estação de Tratamento de Esgoto de Bertioga. A análise das amostras, realizada de acordo com a norma CETESB P 4.230, mostrou que o lodo em questão apresentou as seguintes características médias: 79,7 dag kg ${ }^{-1}$ de umidade; 59,8 dag kg-1 de sólidos voláteis; $\mathrm{pH}$ de 8,2; 302,8 $\mathrm{g} \mathrm{kg}^{-1} \mathrm{de}$ CO; 26,1 $\mathrm{g} \mathrm{kg}^{-1}$ de P; 21,3 $\mathrm{g} \mathrm{kg}^{-1}$ de Ca; 7,3 g kg-1 de $\mathrm{S} ; 7,0 \mathrm{~g} \mathrm{~kg}^{-1} \mathrm{de} \mathrm{Mg}$; 3,3 $\mathrm{g} \mathrm{kg}^{-1}$ de K; 0,5 $\mathrm{g} \mathrm{kg}^{-1} \mathrm{de} \mathrm{Na}$; $793,2 \mathrm{mg} \mathrm{kg}^{-1}$ de $\mathrm{Mn} ; 555,1 \mathrm{mg} \mathrm{kg}^{-1}$ de $\mathrm{Zn}$; $163,6 \mathrm{mg} \mathrm{kg}^{-1}$ de Cu$; 63,9 \mathrm{mg} \mathrm{kg}^{-1}$ de Fe; $55,2 \mathrm{mg} \mathrm{kg}^{-1}$ de $\mathrm{Pb} ; 29,7 \mathrm{mg} \mathrm{kg}^{-1}$ de $\mathrm{Cr} ; 16,9 \mathrm{mg} \mathrm{kg}^{-1}$ de Ni; $12 \mathrm{mg} \mathrm{kg}^{-1}$ de Al; 9,4 mg kg${ }^{-1}$ de Bo; $2,3 \mathrm{mg} \mathrm{kg}^{-1} \mathrm{de}$ $\mathrm{Cd}$; e quantidades inferiores a $0,01 \mathrm{mg} \mathrm{kg}^{-1} \mathrm{de} \mathrm{As} \mathrm{Hg}$, Mo e Se. Em relação ao N, detectaram-se: $40,1 \mathrm{~g} \mathrm{~kg}^{-1}$ de $\mathrm{N}_{\mathrm{KJ}}, 4,60 \mathrm{~g} \mathrm{~kg}^{-1}$ de $\mathrm{N}_{\mathrm{NH} 4+}$ e $48,9 \mathrm{mg} \mathrm{kg}^{-1}$ de $\mathrm{N}_{\mathrm{NO} 3-}$

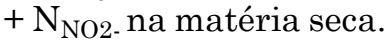

Para seleção das doses de esgoto a serem testadas, deu-se destaque à quantidade de $\mathrm{N}$ disponível no lodo, por ser este o elemento ao qual a pupunheira é mais responsiva (Deenik et al., 2000; Bovi et al., 2002; Ares et al., 2003). Dessa forma, as doses de lodo de esgoto foram determinadas levando-se em consideração a quantidade de $\mathrm{N}$ recomendada anualmente para o cultivo (Bovi \& Cantarella, 1996; Oliveira et al., 2001; Schroth et al., 2002; Ares et al., 2003), a composição química média do lodo utilizado, especialmente com relação ao N, e a fórmula apresentada por Tsutiya (2001), descrita a seguir:

$$
\mathrm{TA}=\mathrm{Np} / \mathrm{Nd}
$$

em que TA: taxa de aplicação $\left(\mathrm{Mg} \mathrm{ha}^{-1}\right)$; $\mathrm{Np}$ : N recomendado para a cultura $\left(\mathrm{kg} \mathrm{ha}^{-1}\right)$; e $\mathrm{Nd}$ : $\mathrm{N}$ disponível no lodo de esgoto $\left(\mathrm{kg} \mathrm{Mg}^{-1}\right)$.

Do ponto de vista econômico e de resposta para a cultura, a quantidade de $\mathrm{N}$ recomendada para a da 
Quadro 1. Características químicas do solo antes e 60 dias após a calagem e 8 e 12 meses após a aplicação incorporada das diferentes doses de lodo de esgoto ${ }^{(1)}$. Amostragem do solo efetuada na camada de 0-20 cm de profundidade

\begin{tabular}{|c|c|c|c|c|c|c|c|c|c|c|c|c|}
\hline \multirow{2}{*}{ Característica } & \multicolumn{3}{|c|}{ Calagem } & \multicolumn{4}{|c|}{8 meses após aplicação } & \multicolumn{5}{|c|}{12 meses após aplicação } \\
\hline & Antes & Após & $\mathbf{T} 1^{(5)}$ & $\mathbf{T} 2$ & T3 & T 4 & $\mathbf{R}^{2(4)}$ & $\mathbf{T} 1^{(5)}$ & $\mathbf{T} 2$ & T 3 & $\mathrm{~T} 4$ & $\mathbf{R}^{2(4)}$ \\
\hline $\mathrm{MO}\left(\mathrm{g} \mathrm{dm}^{-3}\right)$ & 28 & 22 & $29,5 \mathrm{~b}$ & $31,0 \mathrm{ab}$ & $30,4 \mathrm{ab}$ & $34,8 \mathrm{a}$ & $0,55 * *$ & $23,2 \mathrm{~b}$ & $23,3 \mathrm{~b}$ & $28,6 \mathrm{ab}$ & $34,7 \mathrm{a}$ & $0,76^{* * *}$ \\
\hline $\mathrm{pH}\left(\mathrm{CaCl}_{2}\right)$ & 4,2 & 5,4 & $5,3 \mathrm{a}$ & $5,3 \mathrm{a}$ & $5,1 \mathrm{a}$ & $5,5 \mathrm{a}$ & ns & $5,1 \mathrm{ab}$ & $5,3 \mathrm{ab}$ & $4,9 \mathrm{~b}$ & $5,7 \mathrm{a}$ & ns \\
\hline $\mathrm{N}-\mathrm{NO}_{3}\left(\mathrm{mg} \mathrm{dm}^{-3}\right)$ & $-(3)$ & - & $6,6 \mathrm{~b}$ & $8,0 \mathrm{~b}$ & $13,1 \mathrm{~b}$ & 35,7 a & $0,81 * * *$ & $4,5 \mathrm{c}$ & $20,9 \mathrm{bc}$ & $39,0 \mathrm{ab}$ & 56,4 a & $0,83 * * *$ \\
\hline $\mathrm{N}-\mathrm{NH}_{4}\left(\mathrm{mg} \mathrm{dm}^{-3}\right)$ & - & - & $2,3 \mathrm{a}$ & $2,8 \mathrm{a}$ & $2,8 \mathrm{a}$ & $3,6 \mathrm{a}$ & $0,40 *$ & $12,9 \mathrm{a}$ & $13,9 \mathrm{a}$ & $12,5 \mathrm{a}$ & $15,4 \mathrm{a}$ & ns \\
\hline $\mathrm{P}($ resina $)\left(\mathrm{mg} \mathrm{dm}^{-3}\right)$ & 18,00 & 7,94 & $21,3 \mathrm{c}$ & $23,5 \mathrm{c}$ & $65,3 \mathrm{~b}$ & $160,8 \mathrm{a}$ & $0,90 * * *$ & $9,0 \mathrm{~b}$ & $44,2 \mathrm{~b}$ & $152,8 \mathrm{ab}$ & 300,4 a & $0,80^{* * *}$ \\
\hline $\mathrm{K}\left(\mathrm{mmol}_{\mathrm{c}} \mathrm{dm}^{-3}\right)$ & 2,36 & 1,60 & $2,5 \mathrm{a}$ & $2,0 \mathrm{a}$ & $2,0 \mathrm{a}$ & $1,7 \mathrm{a}$ & $-0,42 *$ & $2,3 \mathrm{a}$ & $1,9 \mathrm{a}$ & $1,8 \mathrm{a}$ & $2,3 \mathrm{a}$ & $\mathrm{ns}$ \\
\hline $\mathrm{Ca}\left(\mathrm{mmol}_{\mathrm{c}} \mathrm{dm}^{-3}\right)$ & 12,0 & 19,8 & $22,2 \mathrm{~b}$ & $21,0 \mathrm{~b}$ & $21,8 \mathrm{~b}$ & 56,8 a & $0,59 * *$ & $11,5 \mathrm{~b}$ & $20,7 \mathrm{~b}$ & $23,3 \mathrm{~b}$ & $68,1 \mathrm{a}$ & $0,68^{* *}$ \\
\hline $\mathrm{Mg}\left(\mathrm{mmol}_{\mathrm{c}} \mathrm{dm}^{-3}\right)$ & 3,0 & 8,9 & $10,0 \mathrm{a}$ & $8,7 \mathrm{a}$ & $8,4 \mathrm{a}$ & $28,6 \mathrm{a}$ & ns & $8,3 \mathrm{a}$ & $9,0 \mathrm{a}$ & $9,5 \mathrm{a}$ & $13,3 \mathrm{a}$ & ns \\
\hline $\mathrm{H}+\mathrm{Al}\left(\mathrm{mmol}_{\mathrm{c}} \mathrm{dm}^{-3}\right)$ & 64,0 & 36,4 & 37,8 a & $39,3 \mathrm{a}$ & $43,0 \mathrm{a}$ & $38,3 \mathrm{a}$ & ns & $41,7 \mathrm{ab}$ & $37,5 \mathrm{ab}$ & $55,1 \mathrm{a}$ & $35,1 \mathrm{~b}$ & $\mathrm{~ns}$ \\
\hline $\mathrm{S}^{-\mathrm{SO}_{4}}\left(\mathrm{mg} \mathrm{dm}^{-3}\right)$ & 8,8 & 9,8 & $10,0 \mathrm{~b}$ & $17,2 b$ & $30,0 \mathrm{a}$ & $36,5 \mathrm{a}$ & $0,61 * *$ & $10,3 \mathrm{~b}$ & $20,3 \mathrm{ab}$ & $41,3 \mathrm{a}$ & $43,8 \mathrm{a}$ & $0,68^{* *}$ \\
\hline $\mathrm{B}\left(\mathrm{mg} \mathrm{dm}^{-3}\right)$ & 0,2 & 0,2 & $0,5 \mathrm{a}$ & $0,5 \mathrm{a}$ & 0,6 a & $0,9 \mathrm{a}$ & $0,48^{*}$ & $1,4 \mathrm{a}$ & $1,9 \mathrm{a}$ & $3,1 \mathrm{a}$ & $2,0 \mathrm{a}$ & $\mathrm{ns}$ \\
\hline $\mathrm{Zn}\left(\mathrm{mg} \mathrm{dm}^{-3}\right)$ & 4,5 & 0,3 & $1,2 \mathrm{~b}$ & $3,2 \mathrm{~b}$ & $4,1 \mathrm{ab}$ & $10,8 \mathrm{a}$ & $0,71 * *$ & $0,3 \mathrm{~b}$ & $2,2 \mathrm{~b}$ & $15,7 \mathrm{a}$ & $17,6 \mathrm{a}$ & $0,76^{* * *}$ \\
\hline $\mathrm{Cu}\left(\mathrm{mg} \mathrm{dm}^{-3}\right)$ & 0,4 & 0,3 & $0,8 \mathrm{~b}$ & $0,8 \mathrm{~b}$ & $1,4 \mathrm{~b}$ & $0,1 \mathrm{a}$ & $0,83^{* * *} *$ & $0,3 \mathrm{~b}$ & $1,0 \mathrm{~b}$ & $3,0 \mathrm{a}$ & $3,9 \mathrm{a}$ & $0,85^{* * *}$ \\
\hline $\mathrm{Cd}\left(\mathrm{mg} \mathrm{dm}^{-3}\right)$ & - & 0,02 & $0,1 \mathrm{~b}$ & $0,1 \mathrm{~b}$ & $0,1 \mathrm{~b}$ & $0,2 \mathrm{a}$ & $0,71 * *$ & $0,01 \mathrm{c}$ & $0,04 \mathrm{c}$ & $0,07 \mathrm{ab}$ & $0,11 \mathrm{a}$ & $0,80^{* * *}$ \\
\hline $\mathrm{Pb}\left(\mathrm{mg} \mathrm{dm}^{-3}\right)$ & - & - & $0,6 \mathrm{a}$ & $0,6 \mathrm{a}$ & $0,8 \mathrm{a}$ & $0,9 \mathrm{a}$ & $0,51 * *$ & $0,6 \mathrm{ab}$ & $0,5 \mathrm{~b}$ & $0,6 \mathrm{ab}$ & $0,8 \mathrm{a}$ & $0,48^{*}$ \\
\hline $\mathrm{Ni}\left(\mathrm{mg} \mathrm{dm}^{-3}\right)$ & - & 0,09 & $0,1 \mathrm{~b}$ & $0,1 \mathrm{~b}$ & $0,2 \mathrm{ab}$ & $0,4 \mathrm{a}$ & $0,68^{* *}$ & $0,02 \mathrm{~b}$ & $0,2 \mathrm{~b}$ & $0,6 \mathrm{a}$ & $0,6 \mathrm{a}$ & $0,82 * * *$ \\
\hline $\mathrm{Fe}\left(\mathrm{mg} \mathrm{dm}^{-3}\right)$ & 49,1 & 32,3 & $68,5 \mathrm{~b}$ & $74,2 \mathrm{~b}$ & $124,4 \mathrm{~b}$ & $246,8 \mathrm{a}$ & $0,82 * * *$ & $31,2 \mathrm{~b}$ & $88,2 \mathrm{~b}$ & $175,0 \mathrm{a}$ & $202,5 \mathrm{a}$ & $0,83 * * *$ \\
\hline $\operatorname{Mn}\left(\mathrm{mg} \mathrm{dm}^{-3}\right)$ & 1,27 & 1,83 & $3,5 \mathrm{~b}$ & $3,3 \mathrm{~b}$ & $4,6 \mathrm{ab}$ & $7,8 \mathrm{a}$ & $0,69^{* *}$ & $3,4 \mathrm{~b}$ & $3,4 \mathrm{~b}$ & $10,5 \mathrm{a}$ & $8,5 \mathrm{ab}$ & $0,51 *$ \\
\hline $\mathrm{Cr}\left(\mathrm{mg} \mathrm{dm}^{-3}\right)$ & 0,02 & 0,02 & $0,03 \mathrm{a}$ & $0,03 \mathrm{a}$ & $0,02 \mathrm{a}$ & $0,05 \mathrm{a}$ & ns & $0,09 \mathrm{a}$ & $0,05 \mathrm{a}$ & $0,04 \mathrm{a}$ & $0,09 \mathrm{a}$ & $\mathrm{ns}$ \\
\hline $\mathrm{S}\left(\mathrm{cmol}_{\mathrm{c}} \mathrm{dm}^{-3}\right)^{(2)}$ & 17,4 & 30,3 & 34,7 a & $31,6 \mathrm{a}$ & $32,2 \mathrm{a}$ & 86,9 a & $0,49 *$ & $22,1 \mathrm{~b}$ & $31,6 \mathrm{~b}$ & $34,6 \mathrm{~b}$ & 83,4 a & $0,67 * *$ \\
\hline $\mathrm{T}\left(\mathrm{cmol}_{\mathrm{c}} \mathrm{dm}^{-3}\right)^{(2)}$ & 81,4 & 66,9 & $72,6 \mathrm{~b}$ & $71,2 \mathrm{~b}$ & $75,4 \mathrm{ab}$ & $125,3 \mathrm{a}$ & $0,58 * *$ & $64,0 \mathrm{~b}$ & $69,3 \mathrm{~b}$ & $89,9 \mathrm{ab}$ & 118,6 a & $0,78^{* * *}$ \\
\hline V $(\%)^{(2)}$ & 21,3 & 47,5 & $47,0 \mathrm{a}$ & $43,8 \mathrm{a}$ & $42,8 \mathrm{a}$ & $63,4 \mathrm{a}$ & $0,40^{*}$ & $34,7 \mathrm{~b}$ & $45,5 \mathrm{ab}$ & $36,6 \mathrm{~b}$ & $67,6 \mathrm{a}$ & $0,59^{* *}$ \\
\hline
\end{tabular}

(1) Médias seguidas da mesma letra na linha não diferem entre si pelo teste de Tukey a $5 \%$, dentro de cada data. (2) $\mathrm{S}$ (soma de bases) $=\mathrm{Ca}+\mathrm{Mg}+\mathrm{K}$; T (capacidade de troca catiônica a pH 7$)=\mathrm{S}+(\mathrm{H}+\mathrm{Al}) ; \mathrm{V}$ (porcentagem de saturação por bases $)=(100 \mathrm{~S} / \mathrm{T}) .{ }^{(3)}$ não determinado. ${ }^{(4)}$ Coeficiente de determinação ( $\left.\mathrm{R}^{2}\right)$ e significância da regressão, modelo linear, sendo ns: não-significativo; * , ** $\mathrm{e}^{* * *}$ significativo pelo teste $\mathrm{F}$ a 5,1 e $0,1 \%$ de probabilidade, respectivamente. (5) $\mathrm{T} 1=0, \mathrm{~T} 2=6,5, \mathrm{~T} 3=13 \mathrm{e} \mathrm{T} 4=26 \mathrm{Mg} \mathrm{ha}^{-1}$ de lodo de esgoto (base seca) aplicado de uma só vez no sulco de plantio.

pupunheira (Np) é de $200 \mathrm{~kg} \mathrm{ha}^{-1} \mathrm{ano}^{-1}$ de N (Bovi \& Cantarella, 1996; Bovi et al., 2002; Schroth et al., 2002; Ares et al., 2003; Nascimento et al., 2005).

No cálculo do $\mathrm{N}$ disponível no lodo de esgoto $(\mathrm{Nd})$ foram utilizadas as equações apresentadas por Tsutiya (2001), considerando o modo de aplicação, conforme descritas a seguir:

1. Cálculo de Nd para aplicação subsuperficial (incorporada)

$$
\begin{aligned}
\mathrm{Nd} & =(\mathrm{FM} / 100) \times\left(\mathrm{N}_{\mathrm{KJ}}-\mathrm{N}_{\mathrm{NH}_{4^{+}}}\right)+ \\
& +\mathrm{N}_{\mathrm{NH}_{4^{+}}}+\left(\mathrm{N}_{\mathrm{NO}_{3^{-}}}+\mathrm{N}_{\mathrm{NO}_{2^{-}}}\right)
\end{aligned}
$$

em que $\mathrm{Nd}$ : $\mathrm{N}$ disponível ( $\mathrm{mg} \mathrm{kg}^{-1}$ de lodo seco); FM: fração de mineralização do $\mathrm{N}(\%) ; \mathrm{N}_{\mathrm{KJ}}$ : N Kjeldahl $\left(\mathrm{mg} \mathrm{kg}^{-1}\right)$, sendo $\mathrm{N}$ Kjeldahl $=\mathrm{N}$ orgânico total $+\mathrm{N}$ amoniacal); $\mathrm{N}_{\mathrm{NH}_{4}+}$ : $\mathrm{N}$ amoniacal (mg kg-1); $\mathrm{e}_{\mathrm{NO}_{3^{-}}}+$ $\mathrm{N}_{\mathrm{NO}_{2}}: \mathrm{N}$ nitrato e nitrito $\left(\mathrm{mg} \mathrm{kg}^{-1}\right)$.

\section{Cálculo de $\mathrm{Nd}$ para aplicação superficial:}

$$
\begin{aligned}
\mathrm{Nd} & =(\mathrm{FM} / 100) \times\left(\mathrm{N}_{\mathrm{KJ}}-\mathrm{N}_{\mathrm{NH}_{4^{+}}}\right)+0,5 \mathrm{~N}_{\mathrm{NH}_{4^{+}}}+ \\
& +\left(\mathrm{N}_{\mathrm{NO}_{3}{ }^{-}}+\mathrm{N}_{\mathrm{NO}_{2}-}\right)
\end{aligned}
$$

em que os termos já foram definidos na equação anterior (na quantificação do $\mathrm{N}$ amoniacal, utiliza-se o fator 0,5 para compensar as perdas por volatilização de amônio nessa forma de aplicação do lodo).

Segundo Tsutiya (2001), o valor da fração de mineralização (FM) pode ser determinado para o lodo de esgoto específico ou adotado de dados da literatura. Para lodos digeridos aerobiamente, como o aqui em questão, esse autor sugere que se adote $30 \%$. Dessa forma, o valor 30 representa a porcentagem de $\mathrm{N}$ disponível no primeiro ano.

Substituindo os valores médios das diferentes formas de $\mathrm{N}\left(40,1 \mathrm{~g} \mathrm{~kg}^{-1}\right.$ de $\mathrm{N}_{\mathrm{KJ}}, 4,60 \mathrm{~g} \mathrm{~kg}^{-1} \mathrm{de}_{\mathrm{NH}_{4}+}$ e $48,9 \mathrm{mg} \mathrm{kg}^{-1} \mathrm{de} \mathrm{N}_{\mathrm{NO}_{3}{ }^{-}}+\mathrm{N}_{\mathrm{NO}_{2}}$ ) nas fórmulas apresentadas, obtém-se o valor em base seca de $13 \mathrm{Mg} \mathrm{ha}^{-1}$ para a aplicação incorporada e $15,4 \mathrm{Mg}^{-1}$ de lodo de esgoto para a aplicação em superfície, ambos os valores equivalentes a $200 \mathrm{~kg}$ de $\mathrm{N}^{-1}$. Os tratamentos empregados, tanto na implantação quanto na adubação de manutenção, corresponderam a $0,0,5,1,0$ e 2,0 vezes a quantidade de $\mathrm{N}$ recomendada para o cultivo (200 kg ha-1 $\left.\mathrm{ano}^{-1} \mathrm{de} \mathrm{N}\right)$.

Na implantação da cultura, as doses crescentes de lodo de esgoto foram testadas em delineamento de blocos ao acaso, com quatro tratamentos (doses) e seis repetições (blocos), com 36 plantas por unidade experimental, sendo consideradas úteis as 16 plantas centrais. Foram empregadas bordaduras duplas ao redor de toda a área experimental. Utilizaram-se plantas de pupunheiras inermes, do ecótipo Putumayo, com 10 meses de idade. Adotou-se a densidade de plantio de 5.000 plantas ha-1, num espaçamento de 1,0 m entre plantas e 2,0 m entre linhas. 
Durante a fase de implantação, os tratamentos foram aplicados de uma única vez no sulco de plantio, adicionando-se $15 \mathrm{~g}$ por planta de cloreto de potássio como fonte de $\mathrm{K}_{2} \mathrm{O}$. As doses de lodo de esgoto em base seca, nessa forma de aplicação (incorporada), foram: de $0,6,5,13,0$ e 26,0 $\mathrm{Mg} \mathrm{ha}^{-1}$. Devido às exigências nutricionais do cultivo (Bovi \& Cantarella, 1996; Deenik et al., 2000; Schroth et al., 2002; Ares et al., 2003), foram feitas adubações complementares trimestrais com $15 \mathrm{~g}$ de cloreto de potássio e $2,4 \mathrm{~g}$ de ácido bórico por planta, com o objetivo de corrigir as possíveis deficiências desses elementos.

As respostas das plantas às doses de lodo foram avaliadas mensalmente por meio da mensuração de uma série de caracteres, entre eles o diâmetro (a $50 \mathrm{~cm}$ do solo) e a altura da haste principal, sendo essa medida efetuada do solo até a inserção da folha bandeira. Com base nessas variáveis, foi estimado o número de hastes aptas à colheita de palmito, levandose em consideração a altura mínima de $1,60 \mathrm{~m}$ e o diâmetro mínimo de $10 \mathrm{~cm}$ das hastes, conforme os critérios propostos por vários autores (Villachica,1996; Mora-Urpi et al., 1997; Bovi ,1998; Flori et al., 2004).

Dezesseis meses após a implantação do experimento, tiveram início as adubações de manutenção com o lodo, sendo mantidas as adubações químicas trimestrais complementares com cloreto de potássio e ácido bórico. Durante essa segunda fase (16 a 40 meses), foi aplicado anualmente lodo de esgoto da mesma procedência e nas mesmas doses anteriormente utilizadas na implantação (equivalentes a $0,0,5,1,0$ e 2,0 vezes a quantidade de $200 \mathrm{~kg} \mathrm{ha}^{-1}$ ano $^{-1}$ de N, recomendada para o cultivo). Em três blocos, as adubações de manutenção foram efetuadas em superfície, ao passo que nos outros três foram abertas valas no centro das entrelinhas, constituindo os fatores. Nessa segunda forma de aplicação, o lodo foi incorporado ao solo numa tentativa de diminuir as prováveis perdas por volatilização de N. No tratamento testemunha (dose zero) desses três blocos, as valas também foram abertas para não mascarar o efeito danoso do corte das raízes da pupunheira. Tomou-se o cuidado de recalcular a quantidade de lodo de esgoto a ser aplicada em cada dose de acordo com o sistema adotado (em superfície ou incorporado), seguindo as fórmulas recomendadas por Tsutiya (2001), anteriormente apresentadas. Dessa forma, a dose máxima anual (correspondente a duas vezes a quantidade de $\mathrm{N}$ recomendada para o cultivo) na aplicação incorporada foi de $26 \mathrm{Mg}^{\mathrm{ha}}{ }^{-1}$, enquanto na aplicação em superfície a máxima foi de $30,8 \mathrm{Mg}^{\mathrm{ha}}{ }^{-1}$ (ambas em base seca).

As respostas da pupunheira à aplicação de lodo na segunda fase foram avaliadas por meio de mensurações periódicas, que se concentraram nas características relacionadas à produção de palmito (número de hastes colhidas, massa e dimensões do palmito de cada haste), seguindo o preconizado por Clement \& Bovi (2000).
A produção total foi considerada como a somatória do palmito em toletes e do resíduo basal. O palmito em toletes é também denominado "de primeira" ou "tipo exportação" e corresponde apenas à massa fresca dos toletes inteiros, completos $(9 \mathrm{~cm}$ de comprimento cada), extraídos da porção imediatamente acima do meristema apical. Segundo Clement \& Bovi (2000), determina-se a característica "qualidade de exportação" por meio da pressão exercida por faca afiada sobre a secção mais grossa do tolete. A faca não encontrará resistência à penetração se aquela secção do palmito contiver apenas tecidos macios. Por sua vez, o resíduo basal, também chamado "coração" ou "palmito caulinar", é a porção do estipe imediatamente abaixo do meristema apical, que é bastante tenra para ser consumida "in natura". Não foi considerado neste estudo a "banda", "resíduo apical" ou "palmito picado", porção menos nobre, porém ainda comestível, constituída de ráquis foliares macias, desprovidas de bainha protetora.

Para propiciar uma visão realista da massa média do palmito e do resíduo basal em função de doses de lodo de esgoto, foi considerada a média de todas as colheitas (outubro de 2002 a novembro de 2004). Os valores acumulados das colheitas periódicas durante dois anos foram transformados em quilos por hectare, levando-se em conta a área de cada parcela, e são apresentados em toneladas por hectare e por ano $\left(\mathrm{Mg} \mathrm{ha}{ }^{-1}\right.$ ano $\left.^{-1}\right)$, para efeito de comparação com resultados observados na literatura e aqueles obtidos por pupunheicultores.

Houve durante as duas fases (implantação e manutenção) monitoramento de algumas características químicas do solo e do tecido foliar, inclusive do palmito. Amostras de solo de cada parcela experimental foram retiradas inicialmente e após a calagem. Novas amostragens foram feitas a cada seis meses. Neste trabalho, apenas os resultados referentes à camada de $0-20 \mathrm{~cm}$ do solo foram utilizados. As amostras foram secas a $45^{\circ} \mathrm{C}$ e peneiradas em peneira de $2 \mathrm{~mm}$ de malha. As análises químicas do solo foram efetuadas seguindo procedimento-padrão do Instituto Agronômico de Campinas (Abreu et al., 2001; Raij \& Quaggio, 2001).

Amostras do tecido foliar foram colhidas em várias datas, com cada amostra por parcela composta por folíolos de seis plantas. Em cada planta, foram coletados 12 folíolos da porção média da segunda folha mais jovem completamente expandida. As amostras compostas, após o preparo convencional, foram analisadas de acordo com os métodos propostos por Bataglia et al. (1983b) e Abreu et al. (2001), sendo os resultados expressos em teores totais. A digestão de $\mathrm{N}$ foi realizada pelo processo de Kjeldahl e para determinação do $\mathrm{S}$, com $\mathrm{HNO}_{3}$ e $\mathrm{H}_{2} \mathrm{O}_{2}$, com aquecimento em forno de microondas, segundo método descrito por Abreu (1997). Outros nutrientes foram analisados à partir da cinza seca dissolvida em solução de $\mathrm{HCl}$ e determinação por espectrofotometria $(\mathrm{P}, \mathrm{B})$, fotometria de chama (K) e espectrometria de emissão 
atômica por plasma de argônio indutivamente acoplado (ICP-AES) (S, Ca, Mg, Cu, Fe, Mn e Zn). A análise do palmito, efetuada em duas épocas, seguiu os mesmos procedimentos, com amostras representadas por seis palmitos por parcela.

Os dados foram analisados estatisticamente, de acordo com o delineamento adotado nas duas fases: blocos ao acaso, com quatro tratamentos (doses) e seis repetições, na primeira fase; e em esquema fatorial (4 x 2), com quatro tratamentos (doses), duas formas de aplicação (superfície e incorporado) sendo adotadas três repetições (blocos), na segunda fase.

Todos os dados foram submetidos à análise de variância e ao teste de média (Tukey a $5 \%$ ), bem como à análise de regressão, seguida de ajuste de função, devido à natureza quantitativa dos tratamentos (tendo doses de lodo de esgoto como variável independente). A escolha da equação de melhor ajuste foi baseada na significância do efeito da regressão, nos desvios da regressão testados pelo teste $\mathrm{F}$ a $5 \%$ e no maior coeficiente de determinação (Snedecor \& Cochran, 1989). Quando da comparação dos resultados obtidos na forma de aplicação (em superfície ou incorporada), foi utilizada análise de variância, com comparação entre médias feita pelo teste F a 5 \% (Steel \& Torrie, 1980). Algumas análises relacionadas à qualidade do palmito, incluindo caracterizações física, química e microbiológica, foram também efetuadas e serão objeto de outro artigo.

\section{RESULTADOS E DISCUSSÃO}

\section{Efeitos do lodo de esgoto na fase de implantação da cultura}

Com a aplicação de lodo de esgoto no sulco de plantio, foi observado aumento nos teores de matéria orgânica, com incremento na capacidade de troca catiônica do solo (CTC). Não houve grandes alterações no $\mathrm{pH}$, bem como na acidez potencial do solo (Quadro 1). Oito e 12 meses após a aplicação do lodo a variação do $\mathrm{pH}$ entre dose mínima e máxima era inferior a 8 e $16 \%$, respectivamente.

A mineralização do $\mathrm{N}$ orgânico e subseqüente nitrificação foi significativa e proporcional às doses aplicadas. Oito e 12 meses após a aplicação do lodo de esgoto, observou-se também aumento nos teores de $\mathrm{P}$, $\mathrm{S}, \mathrm{Zn}, \mathrm{Cu}, \mathrm{Fe}, \mathrm{Ni}$ e $\mathrm{Mn}$, corroborando as afirmações de Melo \& Marques (2000) e de Berton \& Camargo (2004), os quais reiteram que o lodo representa um reservatório de nutrientes que são gradativamente liberados durante o processo de mineralização da matéria orgânica.

Os incrementos significativos nos teores de Ca são provavelmente decorrentes do processo de obtenção do lodo (calagem). Em decorrência desses maiores teores, observou-se também incremento significativo, proporcional às doses aplicadas, na soma de bases, bem como na saturação por bases, corroborando resultados de Silva et al. (2001). Por sua vez, visto que o lodo possui baixo teor de $\mathrm{K}$, mesmo com a adição de cloreto de potássio durante o plantio e depois a cada três meses, observa-se que os teores de $\mathrm{K}$ no solo estiveram sempre baixos.

Os teores de alguns elementos potencialmente tóxicos, entre eles os metais pesados $\mathrm{Cd}, \mathrm{Pb}$ e Ni, aumentaram significativamente de acordo com as doses de lodo aplicadas durante o plantio. No entanto, eles foram muito inferiores aos limites máximos estabelecidos pela CETESB (2001) para o Estado de São Paulo. Acúmulo de metais pesados após a adição de lodo de esgoto vem sendo reportado por vários autores, limitando, em alguns casos, a aplicação de doses elevadas desse resíduo (Higgins, 1984; Bertoncini \& Mattiazzo, 1999; Keller et al., 2002; Molina, 2004).

Oito meses após a aplicação, constatou-se que o aumento da fertilidade do solo, proporcionado pela aplicação de lodo de esgoto no plantio, refletiu em aumento nos teores foliares apenas de $\mathrm{N}$ e $\mathrm{Mn}$, evidenciando o potencial do lodo de esgoto em fornecer esses nutrientes à pupunheira (Quadro 2). Por sua vez, para $\mathrm{Cu}, \mathrm{Zn}$ e $\mathrm{Cr}$, houve mesmo redução dos teores foliares desses elementos de acordo com as doses aplicadas. Redução significativa também foi observada para K, tanto aos 8 quanto aos 12 meses após aplicação do lodo, sugerindo que a demanda por esse elemento é grande em pupunheira. De forma geral, todos os elementos, em todas as doses, estiveram dentro da faixa dos teores adequados para a pupunheira, conforme preconizado por alguns autores (Bovi \& Cantarella, 1996; Deenik et al., 2000; Schroth et al., 2002; Ares et al., 2003). Os teores de B aos 12 meses após o plantio estavam um pouco acima daqueles adequados para o cultivo (10 a $40 \mathrm{mg} \mathrm{kg}^{-1}$ ), embora não tenham sido observados sintomas de fitotoxidade. Não houve efeitos significativos das doses de lodo nos teores foliares de alguns elementos potencialmente tóxicos, como $\mathrm{Cd}, \mathrm{Pb}$ e Ni, sendo isso compatível com a qualidade química do lodo estudado, o qual, de acordo com os padrões da CETESB (2001), apresenta teores desses metais abaixo dos limites restritivos ao uso agrícola.

Os efeitos de doses de lodo de esgoto, aplicadas de uma única vez durante o plantio, tiveram reflexos diretos sobre a precocidade de colheita de palmito da pupunheira, o que pode ser visualizado no quadro 3. Essa característica, avaliada pela porcentagem de hastes aptas à colheita, segundo os critérios descritos por Villachica (1996), Mora-Urpi et al. (1997), Bovi (1998) e Flori et al. (2004), começou a ser contabilizada a partir do décimo mês do plantio, quando $1 \%$ das plantas da maior dose estava apto para corte. Do $11^{\circ}$ ao $15^{\circ}$ - mês após a aplicação de lodo de esgoto no sulco de plantio, os efeitos das doses crescentes foram lineares, passando a quadráticos do $16^{\circ}$ ao $18^{\circ}$ mês, em virtude do desenvolvimento gradativo das plantas, com alcance do ponto de corte também para as doses mais baixas.

Nota-se, logo aos 12 meses, superioridade da dose de $26 \mathrm{Mg} \mathrm{ha}^{-1} \mathrm{ano}^{-1}$ (T4), significativa a $1 \%$. Um ano 
Quadro 2. Teores foliares médios de macro e micronutrientes e metais pesados em pupunheiras 8 e 12 meses após a aplicação incorporada das diferentes doses de lodo de esgoto e teores considerados adequados para a cultura ${ }^{(1)}$

\begin{tabular}{|c|c|c|c|c|c|c|c|c|c|c|c|}
\hline \multirow{2}{*}{ Elemento } & \multicolumn{5}{|c|}{8 meses após aplicação } & \multicolumn{5}{|c|}{12 meses após aplicação } & \multirow{2}{*}{ Teor adequado $o^{(3)}$} \\
\hline & $\mathrm{T} 1^{(4)}$ & T2 2 & T3 & T4 & $\mathbf{R}^{2(2)}$ & $\mathrm{T} 1^{(4)}$ & T2 & T3 & T4 & $\mathbf{R}^{2(2)}$ & \\
\hline $\mathrm{N}\left(\mathrm{g} \mathrm{kg}^{-1}\right)$ & $37,9 \mathrm{~b}$ & $38,8 \mathrm{ab}$ & $41,1 \mathrm{a}$ & $40,8 \mathrm{ab}$ & $0,51 * *$ & 35,0 a & 35,4 a & $35,2 \mathrm{a}$ & 36,2 a & $\mathrm{ns}$ & $22-40$ \\
\hline$P\left(\mathrm{~g} \mathrm{~kg}^{-1}\right)$ & 2,7 a & $2,8 \mathrm{a}$ & $2,8 \mathrm{a}$ & 2,7 a & $\mathrm{ns}$ & $2,2 \mathrm{a}$ & $2,3 \mathrm{a}$ & $2,4 \mathrm{a}$ & $2,3 \mathrm{a}$ & $\mathrm{ns}$ & $1,3-3,0$ \\
\hline $\mathrm{K}\left(\mathrm{g} \mathrm{kg}^{-1}\right)$ & $12,9 \mathrm{a}$ & $11,8 \mathrm{ab}$ & $11,1 \mathrm{bc}$ & $10,4 \mathrm{c}$ & $-0,76^{* * *}$ & $12,0 \mathrm{a}$ & $10,4 \mathrm{~b}$ & $9,7 \mathrm{~b}$ & $9,1 \mathrm{~b}$ & $-0,72^{* * *}$ & $8-20$ \\
\hline $\mathrm{Ca}\left(\mathrm{g} \mathrm{kg}^{-1}\right)$ & $4,2 \mathrm{a}$ & $4,3 \mathrm{a}$ & $4,9 \mathrm{a}$ & $4,6 \mathrm{a}$ & $\mathrm{ns}$ & $2,0 \mathrm{a}$ & $2,0 \mathrm{a}$ & $2,1 \mathrm{a}$ & $2,3 \mathrm{a}$ & $\mathrm{ns}$ & $2-6$ \\
\hline $\mathrm{Mg}\left(\mathrm{g} \mathrm{kg}^{-1}\right)$ & $4,1 \mathrm{a}$ & $4,1 \mathrm{a}$ & $4,4 \mathrm{a}$ & $3,8 \mathrm{a}$ & $\mathrm{ns}$ & $1,6 \mathrm{a}$ & $1,6 \mathrm{a}$ & $1,6 \mathrm{a}$ & $1,6 \mathrm{a}$ & $\mathrm{ns}$ & $1,5-5,0$ \\
\hline $\mathrm{S}\left(\mathrm{g} \mathrm{kg}^{-1}\right)$ & $2,1 \mathrm{a}$ & $2,4 \mathrm{a}$ & $2,6 \mathrm{a}$ & $2,5 \mathrm{a}$ & $\mathrm{ns}$ & $2,6 \mathrm{a}$ & $2,7 \mathrm{a}$ & 2,7 a & $2,7 \mathrm{a}$ & $\mathrm{ns}$ & $1,5-3,0$ \\
\hline B $\left(\mathrm{mg} \mathrm{kg}^{-1}\right)$ & $30,0 \mathrm{a}$ & $29,3 \mathrm{a}$ & $30,0 \mathrm{a}$ & $30,2 \mathrm{a}$ & $\mathrm{ns}$ & $47,8 \mathrm{a}$ & $51,3 \mathrm{a}$ & $50,1 \mathrm{a}$ & $54,4 \mathrm{a}$ & $\mathrm{ns}$ & $10-40$ \\
\hline $\mathrm{Cu}\left(\mathrm{mg} \mathrm{kg}^{-1}\right)$ & $8,5 \mathrm{a}$ & $8,2 \mathrm{a}$ & $8,1 \mathrm{a}$ & $7,1 \mathrm{~b}$ & $-0,62^{* *}$ & $5,2 \mathrm{a}$ & $4,9 \mathrm{a}$ & $4,8 \mathrm{a}$ & $4,3 \mathrm{a}$ & $-0,51^{* *}$ & $4-15$ \\
\hline $\mathrm{Fe}\left(\mathrm{mg} \mathrm{kg}^{-1}\right)$ & 90,2 a & 89,7 a & $95,0 \mathrm{a}$ & $93,7 \mathrm{a}$ & $\mathrm{ns}$ & $64,5 \mathrm{a}$ & $64,7 \mathrm{a}$ & $4,8 \mathrm{a}$ & $65,2 \mathrm{a}$ & $\mathrm{ns}$ & $40-200$ \\
\hline $\mathrm{Mn}\left(\mathrm{mg} \mathrm{kg}^{-1}\right)$ & 59,3 a & 55,2 a & $65,8 \mathrm{a}$ & 66,5 a & $0,42^{*}$ & $31,5 \mathrm{a}$ & $31,2 \mathrm{a}$ & $34,0 \mathrm{a}$ & $36,2 \mathrm{a}$ & $0,53^{* *}$ & $30-200$ \\
\hline $\mathrm{Zn}\left(\mathrm{mg} \mathrm{kg}^{-1}\right)$ & 29,9 a & $27,5 \mathrm{ab}$ & $25,7 \mathrm{bc}$ & $24,1 \mathrm{c}$ & $-0,62^{* *}$ & $19,5 \mathrm{a}$ & $19,2 \mathrm{a}$ & $18,1 \mathrm{a}$ & $18,3 \mathrm{a}$ & $\mathrm{ns}$ & $15-50$ \\
\hline $\mathrm{Cd}\left(\mathrm{mg} \mathrm{kg}^{-1}\right)$ & $0,2 \mathrm{a}$ & $0,3 \mathrm{a}$ & $0,3 \mathrm{a}$ & $0,4 \mathrm{a}$ & $\mathrm{ns}$ & $0,0 \mathrm{a}$ & $0,0 \mathrm{a}$ & $0,0 \mathrm{a}$ & $0,0 \mathrm{a}$ & $\mathrm{ns}$ & $<1,0$ \\
\hline $\mathrm{Pb}\left(\mathrm{mg} \mathrm{kg}^{-1}\right)$ & 2,7 a & $1,6 \mathrm{a}$ & $0,7 \mathrm{a}$ & $2,2 \mathrm{a}$ & ns & $0,3 \mathrm{a}$ & $1,0 \mathrm{a}$ & $0,5 \mathrm{a}$ & $0,7 \mathrm{a}$ & $\mathrm{ns}$ & $<0,8$ \\
\hline $\mathrm{Ni}\left(\mathrm{mg} \mathrm{kg}^{-1}\right)$ & $0,5 \mathrm{a}$ & $0,9 \mathrm{a}$ & $0,3 \mathrm{a}$ & $0,7 \mathrm{a}$ & $\mathrm{ns}$ & $0,0 \mathrm{a}$ & $0,0 \mathrm{a}$ & $0,0 \mathrm{a}$ & $0,0 \mathrm{a}$ & $\mathrm{ns}$ & $<0,5$ \\
\hline $\mathrm{Cr}\left(\mathrm{mg} \mathrm{kg}^{-1}\right)$ & $0,7 \mathrm{a}$ & $0,7 \mathrm{a}$ & $0,4 \mathrm{a}$ & $0,2 \mathrm{a}$ & $-0,44^{*}$ & $0,0 \mathrm{a}$ & $0,2 \mathrm{a}$ & $0,3 \mathrm{a}$ & $0,2 \mathrm{a}$ & $\mathrm{ns}$ & $<0,1$ \\
\hline
\end{tabular}

(1) Médias seguidas da mesma letra na linha não diferem entre si pelo teste de Tukey a $5 \%$, dentro de cada data. ${ }^{(2)}$ Coeficiente de determinação $\left(\mathrm{R}^{2}\right)$ e significância da regressão, modelo linear, sendo ns: não-significativo; *,$* * \mathrm{e} * * *$ significativos pelo teste $\mathrm{F}$ a 5,1 e $0,1 \%$, respectivamente. ${ }^{(3)}$ Teores adequados para a pupunheira segundo Bovi \& Cantarella (1996), Deenik et al. (2000), Ares et al. (2002) e Schroth et al. (2002). ${ }^{(4)} \mathrm{T} 1=0, \mathrm{~T} 2=6,5, \mathrm{~T} 3=13 \mathrm{e} \mathrm{T} 4=26 \mathrm{Mg}^{-1}$ de lodo de esgoto (base seca) aplicado de uma só vez no sulco de plantio.

após o plantio, cerca de $15,62 \%$ das plantas que receberam a maior dose de lodo de esgoto estavam aptas para colheita de palmito. Nessa data, na testemunha (dose 0), nenhuma planta tinha ainda alcançado o ponto de corte, enquanto nas doses de 6,5 e $13 \mathrm{Mg} \mathrm{ha}{ }^{-1}$ ano $^{-1}$ a porcentagem de plantas aptas também era reduzida (1,04 e 2,08\%, respectivamente). Os efeitos das menores doses de lodo (6,5 e $13 \mathrm{Mg} \mathrm{ha}^{-1}$ ano $^{-1}$ ) somente se mostraram estatisticamente diferentes da testemunha a partir do $15^{\circ}$ - mês após a aplicação. Nessa idade, 59,65\% das plantas do tratamento que receberam $26 \mathrm{Mg} \mathrm{ha}^{-1} \mathrm{ano}^{-1}$ estavam aptas para corte. Por sua vez, as doses de 6,5 e $13 \mathrm{Mg}$ ha $^{-1}$ ano $^{-1}$ apresentavam, respectivamente, 42,99 e $34,37 \%$ de plantas aptas à colheita (estatisticamente iguais à maior dose), enquanto no tratamento sem lodo de esgoto (dose 0) essa porcentagem era de $7,29 \%$.

Os resultados demonstram que o uso do lodo de esgoto apenas durante a implantação do cultivo pode acelerar o tempo de colheita do palmito. Conforme relatado por vários autores (Villachica, 1996; MoraUrpi et al., 1997; Bovi, 1998; Flori et al., 2004), a colheita de palmito de um cultivo de pupunheira deve ser iniciada assim que pelos menos $10 \%$ das plantas possuam hastes em ponto de corte. Nota-se, pelo quadro 3, que esse patamar (10\% de plantas aptas para colheita) foi atingido aos 12 meses no tratamento T4, com dose correspondente a duas vezes a necessidade de $\mathrm{N}$ da cultura (NC), aos 14 meses na NC recomendada (T3), aos 15 meses na dose equivalente a 0,5 da $\mathrm{NC}$ (T2) e somente acima de 15 meses na dose 0. Com o uso de lodo de esgoto na implantação do cultivo ganha-se, portanto, de um a quatro meses em precocidade de corte. Tais resultados são de fato relevantes, visto que, quanto antes for iniciada a colheita, mais rapidamente o agricultor passará da fase de desembolso para a fase de lucro, uma vez que a implantação da cultura é onerosa, representando em torno de 60 a $70 \%$ do investimento feito no prazo de 10 anos (AGRIANUAL, 2005). Além disso, dada a variabilidade genética do material disponível aos agricultores e a densidade recomendada para o cultivo (5.000 a 6.600 plantas por hectare), cortes precoces favorecem o desenvolvimento das outras plantas, permitem melhor desenvolvimento dos perfilhos e proporcionam maior periodicidade de colheita (Mora-Urpi et al., 1997; Bovi, 1998; Flori et al., 2004).

Por se tratar do primeiro experimento feito com lodo de esgoto em pupunheira, não foram encontrados resultados comparativos na literatura. No entanto, as porcentagens de plantas aptas à colheita obtidas no presente experimento foram superiores às relatadas por Bovi et al. (2000) quando do uso de composto de lixo urbano no cultivo dessa palmeira, em ensaio realizado na mesma região climática (Ubatuba, SP), com material genético da mesma origem, porém em solo com menor fertilidade. Para doses de composto de lixo aplicadas também de uma única vez no sulco de plantio, Bovi et al. (2000) obtiveram, aos 17 meses após o plantio, efeito linear crescente de acordo com as doses, com máximo de 45,73\% de plantas aptas para corte alcançado na dose de $28,56 \mathrm{Mg} \mathrm{ha}^{-1}$ de 
composto de lixo (base seca). Nessa mesma idade, as porcentagens de plantas aptas à colheita no ensaio de lodo de esgoto foram superiores a $80 \%$.

A maior porcentagem de plantas aptas nos tratamentos com aplicação de doses de lodo de esgoto no sulco de plantio é, sem dúvida, conseqüência da melhoria da fertilidade do solo (Quadro 1), que se refletiu em aumento nos teores foliares de alguns nutrientes (Quadro 2), especialmente $\mathrm{N}$ e Mn. As palmeiras são bastante responsivas à adubação nitrogenada, seja esta na forma orgânica ou mineral (Manciot et al., 1980; Secretaria \& Maravilla, 1997; Ramos, 2002), com reflexos diretos no crescimento vegetativo e na produção (Ollagnier et al., 1970; Tampubolon et al., 1990; Deenik et al., 2000; Bovi et al., 2002; Schroth et al., 2002; Ares et al., 2003; Nascimento et al., 2005).

Houve, também nessa fase de implantação, melhoria em algumas propriedades físicas do solo, contribuindo para o aumento e o aprofundamento do sistema radicular, conforme constatado por Vega et al. (2005).

\section{Efeitos do lodo de esgoto na fase de manutenção da cultura}

No quadro 4 estão sumarizadas as características químicas do solo (camada de 0 a $20 \mathrm{~cm}$ ) em análise efetuada três meses após a segunda aplicação anual do lodo (28 meses após o plantio). Nota-se que a aplicação de doses anuais de lodo de esgoto, tanto em superfície quanto incorporada, durante a fase de manutenção da cultura proporcionou aumento nos teores de matéria orgânica, $\mathrm{P}, \mathrm{Ca}, \mathrm{Zn}, \mathrm{Cu}, \mathrm{Fe}$ e $\mathrm{Mn}$ e contribuiu para o incremento na soma de bases, na capacidade de troca catiônica e na saturação por bases do solo (Quadro 4). Da mesma forma quando da aplicação no sulco de plantio, não houve alterações significativas no $\mathrm{pH}$ do solo. As alterações nesse $\mathrm{pH}$, de acordo com as doses, foram menores quando o lodo foi incorporado, em relação àquele disposto em superfície. Os teores de K no solo se mantiveram baixos e, especialmente na aplicação de lodo de esgoto na forma incorporada, houve decréscimo significativo desse elemento de acordo com as doses. Os teores dos elementos potencialmente tóxicos foram baixos, atestando, mais uma vez, a boa qualidade do lodo de esgoto utilizado.

A avaliação dos teores foliares dos nutrientes durante essa fase (Quadro 5) evidenciou ausência de efeitos lineares de doses, com todos os elementos estando dentro da faixa de teores considerados adequados ao cultivo (Bovi \& Cantarella, 1996; Deenik et al., 2000; Schroth et al., 2002; Ares et al., 2003). Apenas nos teores foliares de $\mathrm{S}$ foi constatado efeito significativo $(\mathrm{P}<0,05)$ negativo em função das doses de lodo de esgoto, quando da aplicação em superfície. Ainda nessa forma de aplicação, o teste de Tukey detectou significância a $5 \%$ entre as médias para os teores foliares dos elementos B, Fe e Mn. De modo geral, não foram constatadas diferenças significativas nos teores foliares (Quadro 5), bem como em grande parte das características químicas do solo (Quadro 4), de acordo com as formas de aplicação do lodo (em superfície ou incorporada).

As respostas das plantas às doses de lodo de esgoto se refletiram, nessa fase, em alguns caracteres diretamente relacionados à produção de palmito. Um deles é a periodicidade de colheita. Na figura 1 é apresentado o número médio anual de hastes colhidas em cada planta, com base nas médias obtidas nas parcelas. Houve efeito linear positivo no número de hastes colhidas de acordo com as doses empregadas. Por exemplo, quando da aplicação do lodo em superfície, observa-se que na ausência de adubação com lodo de esgoto (testemunha) apenas 0,5 haste foi colhida anualmente, enquanto na maior dose foi

Quadro 3. Porcentagens de plantas aptas à colheita obtidas no período de 10 a 18 meses após a aplicação incorporada das diferentes doses de lodo de esgoto ${ }^{(1)}$

\begin{tabular}{|c|c|c|c|c|c|c|c|}
\hline \multirow{2}{*}{ Meses após plantio } & \multicolumn{5}{|c|}{ Plantas aptas à colheita (\%) } & \multicolumn{2}{|c|}{ Regressão } \\
\hline & $\mathrm{T} 1^{(4)}$ & T2 & T3 & $\mathbf{T} 4$ & F para doses & Modelo (2) $^{(2)}$ & $\mathbf{R}^{2(3)}$ \\
\hline 10 & $0 \mathrm{a}$ & $0 \mathrm{a}$ & $0 \mathrm{a}$ & $1,04 \mathrm{a}$ & $1,00 \mathrm{~ns}$ & - & ns \\
\hline 11 & $0 \mathrm{a}$ & $0 \mathrm{a}$ & $0 \mathrm{a}$ & $2,08 \mathrm{a}$ & $2,50 \mathrm{~ns}$ & $\mathrm{~L}$ & $0,46^{*}$ \\
\hline 12 & $0 \mathrm{~b}$ & $1,04 \mathrm{~b}$ & $2,08 \mathrm{~b}$ & $15,62 \mathrm{a}$ & $7,23^{* *}$ & $\mathrm{~L}$ & $0,66^{* *}$ \\
\hline 13 & $0 \mathrm{~b}$ & $1,04 \mathrm{~b}$ & $3,12 \mathrm{~b}$ & $27,08 \mathrm{a}$ & $7,36^{* *}$ & $\mathrm{~L}$ & $0,66^{* *}$ \\
\hline 14 & $1,04 \mathrm{~b}$ & $9,37 \mathrm{~b}$ & $10,42 \mathrm{~b}$ & $44,79 \mathrm{a}$ & $21,85^{* * *}$ & $\mathrm{~L}$ & $0,81^{* * *}$ \\
\hline 15 & $7,29 \mathrm{~b}$ & $34,37 \mathrm{ab}$ & $42,99 \mathrm{a}$ & $59,65 \mathrm{a}$ & $7,97 * *$ & $\mathrm{~L}$ & $0,70 * *$ \\
\hline 16 & $33,47 \mathrm{~b}$ & $64,58 \mathrm{a}$ & $73,26 \mathrm{a}$ & $81,87 \mathrm{a}$ & $15,88^{* * *}$ & $\mathrm{Q}$ & $0,59 * *$ \\
\hline 17 & $58,89 \mathrm{~b}$ & $80,21 \mathrm{a}$ & $82,92 \mathrm{a}$ & $83,96 \mathrm{a}$ & $5,91 * *$ & $\mathrm{Q}$ & $0,35^{*}$ \\
\hline 18 & $75,76 \mathrm{~b}$ & $88,54 \mathrm{ab}$ & $93,68 \mathrm{a}$ & $86,11 \mathrm{ab}$ & $4,01^{*}$ & Q & $0,35^{*}$ \\
\hline
\end{tabular}

(1) Médias seguidas da mesma letra na linha não diferem entre si pelo teste de Tukey a $5 \%$. (2) Modelo de melhor ajuste, sendo L = linear, $\mathrm{Q}=$ quadrático. ${ }^{(3)}$ Coeficiente de determinação $\left(\mathrm{R}^{2}\right)$ e significância da regressão, sendo ns: não-significativo; * , ** e *** significativo pelo teste $\mathrm{F}$ a 5,1 e $0,1 \%$, respectivamente. ${ }^{(4)} \mathrm{T} 1=0, \mathrm{~T} 2=6,5, \mathrm{~T} 3=13$ e $\mathrm{T} 4=26 \mathrm{Mg}^{-1}$ de lodo de esgoto (base seca) aplicado de uma só vez no sulco de plantio. 
Quadro 4. Características químicas do solo três meses após a segunda aplicação em superfície e incorporada das diferentes doses de lodo de esgoto ${ }^{(1)}$. Amostragem do solo efetuada na camada de 0-20 cm de profundidade

\begin{tabular}{|c|c|c|c|c|c|c|c|c|c|c|}
\hline & \multicolumn{4}{|c|}{ Aplicação em superfície } & \multirow{2}{*}{$\begin{array}{c}\text { Regressão } \\
\mathbf{R}^{2(3)}\end{array}$} & \multicolumn{4}{|c|}{ Aplicação incorporada } & \multirow{2}{*}{$\begin{array}{c}\text { Regressão } \\
\mathbf{R}^{2(3)}\end{array}$} \\
\hline & T1 ${ }^{(4)}$ & T2 & T3 & T4 & & T1 ${ }^{(4)}$ & $\mathrm{T} 2$ & T3 & $\mathrm{T} 4$ & \\
\hline $\operatorname{MO}\left(\mathrm{g} \mathrm{dm}^{-3}\right)$ & $22,3 \mathrm{a}$ & $24,3 \mathrm{a}$ & 24,7 a & $31,0 \mathrm{a}$ & $0,60^{*}$ & $23,0 \mathrm{~b}$ & $26,7 \mathrm{~b}$ & $25,0 \mathrm{~b}$ & $32,7 \mathrm{a}$ & $0,75^{* *}$ \\
\hline $\mathrm{pH}\left(\mathrm{CaCl}_{2}\right)$ & $4,9 \mathrm{a}$ & $5,4 \mathrm{a}$ & $4,8 \mathrm{a}$ & $5,7 \mathrm{a}$ & $\mathrm{ns}$ & $4,8 \mathrm{a}$ & $4,9 \mathrm{a}$ & $5,1 \mathrm{a}$ & $5,1 \mathrm{a}$ & $\mathrm{ns}$ \\
\hline $\mathrm{NNO}_{3} \mathrm{NO}_{2}\left(\mathrm{mg} \mathrm{dm}^{-3}\right)$ & 4,7 & 4,0 & 7,8 & 3,4 & $\mathrm{~ns}$ & 4,7 & 6,8 & 5,0 & 7,8 & $\mathrm{~ns}$ \\
\hline $\mathrm{N}-\mathrm{NH}_{4}\left(\mathrm{mg} \mathrm{dm}^{-3}\right)$ & 4,9 & 3,8 & 5,9 & 4,2 & $\mathrm{~ns}$ & 3,8 & 6,1 & 6,4 & 6,2 & $\mathrm{~ns}$ \\
\hline $\mathrm{P}_{(\mathrm{resina})}\left(\mathrm{mg} \mathrm{dm}^{-3}\right)$ & $6,3 \mathrm{~d}$ & $50,3 \mathrm{c}$ & $98,3 \mathrm{~b}$ & $163,3 \mathrm{a}$ & $0,99^{* * *}$ & $9,0 \mathrm{~b}$ & $59,7 \mathrm{ab}$ & $95,7 \mathrm{~b}$ & $157,3 \mathrm{a}$ & $0,95^{* * *}$ \\
\hline $\mathrm{K}\left(\mathrm{mmol}_{\mathrm{c}} \mathrm{dm}^{-3}\right)$ & $7,8 \mathrm{a}$ & $7,8 \mathrm{a}$ & $8,2 \mathrm{a}$ & $7,0 \mathrm{a}$ & $\mathrm{ns}$ & $10,3 \mathrm{a}$ & $9,0 \mathrm{a}$ & $6,7 \mathrm{a}$ & $6,8 \mathrm{a}$ & $-0,61^{*}$ \\
\hline $\mathrm{Ca}\left(\mathrm{mmol}_{\mathrm{c}} \mathrm{dm}^{-3}\right)$ & $9,3 \mathrm{a}$ & $15,0 \mathrm{a}$ & $13,3 \mathrm{a}$ & $67,0 \mathrm{a}$ & $0,74^{* *}$ & $9,3 \mathrm{a}$ & $15,0 \mathrm{a}$ & $11,0 \mathrm{a}$ & $32,3 \mathrm{a}$ & $0,74^{* *}$ \\
\hline $\mathrm{Mg}\left(\mathrm{mmol}_{\mathrm{c}} \mathrm{dm}^{-3}\right)$ & $5,7 \mathrm{a}$ & $6,3 \mathrm{a}$ & $5,0 \mathrm{a}$ & $7,7 \mathrm{a}$ & $\mathrm{ns}$ & $5,3 \mathrm{ab}$ & $5,7 \mathrm{ab}$ & $4,3 \mathrm{~b}$ & $6,3 \mathrm{a}$ & $\mathrm{ns}$ \\
\hline $\mathrm{H}+\mathrm{Al}\left(\mathrm{mmol}_{\mathrm{c}} \mathrm{dm}^{-3}\right)$ & 39,3 a & $38,3 \mathrm{a}$ & $50,7 \mathrm{a}$ & $34,0 \mathrm{a}$ & $\mathrm{ns}$ & $39,3 \mathrm{a}$ & $45,3 \mathrm{a}$ & $52,7 \mathrm{a}$ & $46,0 \mathrm{a}$ & $\mathrm{ns}$ \\
\hline B $\left(\mathrm{mg} \mathrm{dm}^{-3}\right)$ & $1,1 \mathrm{a}$ & $0,8 \mathrm{a}$ & $4,3 \mathrm{a}$ & $1,2 \mathrm{a}$ & $\mathrm{ns}$ & $1,4 \mathrm{a}$ & $7,4 \mathrm{a}$ & $1,7 \mathrm{a}$ & $2,6 \mathrm{a}$ & $\mathrm{ns}$ \\
\hline $\mathrm{Zn}\left(\mathrm{mg} \mathrm{dm}{ }^{-3}\right)$ & $0,8 \mathrm{a}$ & $1,1 \mathrm{a}$ & $4,1 \mathrm{a}$ & $4,8 \mathrm{a}$ & $0,64^{*}$ & $0,4 \mathrm{~b}$ & $2,2 \mathrm{~b}$ & $3,3 \mathrm{ab}$ & $10,3 \mathrm{a}$ & $0,88^{* *}$ \\
\hline $\mathrm{Cu}\left(\mathrm{mg} \mathrm{dm}^{-3}\right)$ & $1,3 \mathrm{a}$ & 1,4 & $2,7 \mathrm{a}$ & $3,0 \mathrm{a}$ & $0,60^{*}$ & $0,9 \mathrm{~b}$ & $2,0 \mathrm{ab}$ & $2,6 \mathrm{ab}$ & $4,6 \mathrm{a}$ & $0,83^{* *}$ \\
\hline $\mathrm{Cd}\left(\mathrm{mg} \mathrm{dm}^{-3}\right)$ & $0,04 \mathrm{a}$ & $0,00 \mathrm{a}$ & $0,02 \mathrm{a}$ & $0,04 \mathrm{a}$ & $\mathrm{ns}$ & $0,10 \mathrm{a}$ & $0,00 \mathrm{a}$ & $0,00 \mathrm{a}$ & $0,00 \mathrm{a}$ & $\mathrm{ns}$ \\
\hline $\mathrm{Pb}\left(\mathrm{mg} \mathrm{dm}^{-3}\right)$ & $0,00 \mathrm{a}$ & $0,00 \mathrm{a}$ & $0,00 \mathrm{a}$ & $0,00 \mathrm{a}$ & $\mathrm{ns}$ & $0,00 \mathrm{a}$ & $0,00 \mathrm{a}$ & $0,00 \mathrm{a}$ & $0,00 \mathrm{a}$ & $\mathrm{ns}$ \\
\hline $\mathrm{Ni}\left(\mathrm{mg} \mathrm{dm}^{-3}\right)$ & $13,6 \mathrm{a}$ & $11,0 \mathrm{a}$ & $16,3 \mathrm{a}$ & $17,9 \mathrm{a}$ & $\mathrm{ns}$ & $16,1 \mathrm{a}$ & $16,7 \mathrm{a}$ & $12,8 \mathrm{a}$ & $12,8 \mathrm{a}$ & $\mathrm{ns}$ \\
\hline $\mathrm{Fe}\left(\mathrm{mg} \mathrm{dm}^{-3}\right)$ & $33,0 \mathrm{a}$ & 79,3 a & 202,7 a & $177,0 \mathrm{a}$ & $0,62^{*}$ & $36,0 \mathrm{~b}$ & $147,0 \mathrm{ab}$ & $152,0 \mathrm{ab}$ & 271,3 a & $0,85^{* *}$ \\
\hline $\operatorname{Mn}\left(\mathrm{mg} \mathrm{dm}^{-3}\right)$ & $2,0 \mathrm{a}$ & $1,9 \mathrm{a}$ & $2,6 \mathrm{a}$ & $2,3 \mathrm{a}$ & $\mathrm{ns}$ & $2,1 \mathrm{a}$ & $2,4 \mathrm{a}$ & $3,2 \mathrm{a}$ & 3,9 a & $0,68^{*}$ \\
\hline Cromo $\left(\mathrm{mmol}_{\mathrm{c}} \mathrm{dm}^{-3}\right)$ & $22,8 \mathrm{a}$ & $17,5 \mathrm{a}$ & $20,0 \mathrm{a}$ & $19,5 \mathrm{a}$ & $\mathrm{ns}$ & $23,7 \mathrm{a}$ & $23,6 \mathrm{a}$ & $21,4 \mathrm{a}$ & $18,1 \mathrm{a}$ & $\mathrm{ns}$ \\
\hline $\mathrm{S}\left(\mathrm{cmol}_{\mathrm{c}} \mathrm{dm}^{-3}\right)^{(2)}$ & $22,8 \mathrm{a}$ & $29,1 \mathrm{a}$ & $26,5 \mathrm{a}$ & $81,7 \mathrm{a}$ & $0,72^{* *}$ & $25,0 \mathrm{a}$ & $29,6 \mathrm{a}$ & $22,0 \mathrm{a}$ & $45,5 \mathrm{a}$ & $0,65^{*}$ \\
\hline $\mathrm{T}\left(\mathrm{cmol}_{\mathrm{c}} \mathrm{dm}^{-3}\right)^{(2)}$ & $62,3 \mathrm{~b}$ & $67,6 \mathrm{~b}$ & $77,2 \mathrm{ab}$ & $115,8 \mathrm{a}$ & $0,85^{* *}$ & $64,6 \mathrm{c}$ & $75,1 \mathrm{~b}$ & $75,0 \mathrm{~b}$ & 91,7 a & $0,86^{* *}$ \\
\hline $\mathrm{V}(\%)^{(2)}$ & 36,3 a & $43,0 \mathrm{a}$ & $34,3 \mathrm{a}$ & $66,7 \mathrm{a}$ & $0,63^{*}$ & $38,7 \mathrm{a}$ & $39,0 \mathrm{a}$ & $29,7 \mathrm{a}$ & 49,3 a & $\mathrm{Ns}$ \\
\hline
\end{tabular}

(1) Médias seguidas da mesma letra na linha não diferem entre si pelo teste de Tukey a $5 \%$, dentro de cada forma de aplicação. ${ }^{(2)} \mathrm{S}$ (soma de bases) $=\mathrm{Ca}+\mathrm{Mg}+\mathrm{K}$; $\mathrm{T}$ (capacidade de troca catiônica a pH 7) $=\mathrm{S}+(\mathrm{H}+\mathrm{Al})$; $\mathrm{V}$ (porcentagem de saturação por bases $)=(100 \mathrm{~S} / \mathrm{T}) .{ }^{(3)}$ Coeficiente de determinação $\left(\mathrm{R}^{2}\right)$ e significância da regressão, modelo linear, sendo ns: não-significativo; *, $* * \mathrm{e}^{* * *}$ significativo pelo teste $\mathrm{F}$ a 5,1 e $0,1 \%$, respectivamente. ${ }^{(4)} \mathrm{T} 1=0, \mathrm{~T} 2=7,7, \mathrm{~T} 3=15,4$ e $\mathrm{T} 4=30,8 \mathrm{Mg}$ ha ${ }^{-1}$ de lodo de esgoto

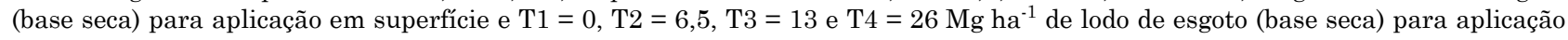
incorporada.

Quadro 5. Teores foliares médios de macro e micronutrientes e metais pesados em pupunheiras três meses após a segunda aplicação em superfície e incorporada das diferentes doses de lodo de esgoto e teores considerados adequados para a cultura ${ }^{(1)}$

\begin{tabular}{|c|c|c|c|c|c|c|c|c|c|c|c|}
\hline \multirow{2}{*}{ Elemento } & \multicolumn{5}{|c|}{ Aplicação em superfície } & \multicolumn{5}{|c|}{ Aplicação incorporada } & \multirow{2}{*}{$\begin{array}{c}\text { Teores } \\
\text { adequados } \\
\end{array}$} \\
\hline & T1 ${ }^{(4)}$ & $\mathrm{T} 2$ & T3 & $\mathbf{T} 4$ & $\mathbf{R}^{2(2)}$ & T1 (4) & $\mathrm{T} 2$ & T3 & T4 & $\overline{\mathrm{R}^{2(2)}}$ & \\
\hline $\mathrm{N}\left(\mathrm{g} \mathrm{kg}^{-1}\right)$ & 33,4 a & $32,3 \mathrm{a}$ & $27,8 \mathrm{a}$ & $33,2 \mathrm{a}$ & $\mathrm{ns}$ & $31,3 \mathrm{a}$ & $33,6 \mathrm{a}$ & $36,2 \mathrm{a}$ & 32,3 a & $\mathrm{ns}$ & $22-40$ \\
\hline$P\left(\mathrm{~g} \mathrm{~kg}^{-1}\right)$ & $2,9 \mathrm{a}$ & $2,6 \mathrm{a}$ & $2,8 \mathrm{a}$ & $2,7 \mathrm{a}$ & $\mathrm{ns}$ & $2,8 \mathrm{a}$ & 2,4 a & $3,0 \mathrm{a}$ & $2,6 \mathrm{a}$ & $\mathrm{ns}$ & $1,3-3,0$ \\
\hline $\mathrm{K}\left(\mathrm{g} \mathrm{kg}^{-1}\right)$ & $11,8 \mathrm{a}$ & $12,9 \mathrm{a}$ & $16,1 \mathrm{a}$ & $12,2 \mathrm{a}$ & $\mathrm{ns}$ & $15,0 \mathrm{a}$ & $15,2 \mathrm{a}$ & $13,2 \mathrm{a}$ & $15,0 \mathrm{a}$ & $\mathrm{ns}$ & $8-20$ \\
\hline $\mathrm{Ca}\left(\mathrm{g} \mathrm{kg}^{-1}\right)$ & 6,4 a & $3,1 \mathrm{a}$ & $2,4 \mathrm{a}$ & $3,7 \mathrm{a}$ & $\mathrm{ns}$ & $3,9 \mathrm{a}$ & $3,6 \mathrm{a}$ & $3,7 \mathrm{a}$ & $2,6 \mathrm{a}$ & $\mathrm{ns}$ & $2-6$ \\
\hline $\mathrm{Mg}\left(\mathrm{g} \mathrm{kg}^{-1}\right)$ & 4,4 a & $2,3 \mathrm{a}$ & $2,0 \mathrm{a}$ & $2,6 \mathrm{a}$ & ns & $2,6 \mathrm{a}$ & $2,6 \mathrm{a}$ & $2,7 \mathrm{a}$ & $2,2 \mathrm{a}$ & $\mathrm{ns}$ & $1,5-5,0$ \\
\hline $\mathrm{S}\left(\mathrm{g} \mathrm{kg}^{-1}\right)$ & 3,7 a & $3,5 \mathrm{ab}$ & $3,3 \mathrm{~b}$ & $3,1 \mathrm{~b}$ & $-0,64^{*}$ & $3,7 \mathrm{a}$ & $4,0 \mathrm{a}$ & $3,5 \mathrm{a}$ & $3,6 \mathrm{a}$ & $\mathrm{ns}$ & $1,5-3,0$ \\
\hline B $\left(\mathrm{mg} \mathrm{kg}^{-1}\right)$ & 26,6 a & $18,6 \mathrm{ab}$ & $16,0 \mathrm{~b}$ & $20,2 \mathrm{ab}$ & $\mathrm{ns}$ & $23,1 \mathrm{a}$ & $24,8 \mathrm{a}$ & $19,7 \mathrm{a}$ & $18,8 \mathrm{a}$ & $\mathrm{ns}$ & $10-40$ \\
\hline $\mathrm{Cu}\left(\mathrm{mg} \mathrm{kg}^{-1}\right)$ & $6,0 \mathrm{a}$ & $5,6 \mathrm{a}$ & $7,2 \mathrm{a}$ & $4,8 \mathrm{a}$ & $\mathrm{ns}$ & $5,2 \mathrm{a}$ & $5,4 \mathrm{a}$ & $5,5 \mathrm{a}$ & $6,6 \mathrm{a}$ & $\mathrm{ns}$ & $4-15$ \\
\hline $\mathrm{Fe}\left(\mathrm{mg} \mathrm{kg}^{-1}\right)$ & 208,3 a & $106,7 \mathrm{ab}$ & $88,3 \mathrm{~b}$ & $117,3 \mathrm{ab}$ & $\mathrm{ns}$ & $117,3 \mathrm{a}$ & 117,7 a & $116,7 \mathrm{a}$ & $87,0 \mathrm{a}$ & $\mathrm{ns}$ & $40-200$ \\
\hline $\operatorname{Mn}\left(\mathrm{mg} \mathrm{kg}^{-1}\right)$ & $58,7 \mathrm{a}$ & $30,0 \mathrm{~b}$ & $29,0 \mathrm{~b}$ & $33,7 \mathrm{ab}$ & $\mathrm{ns}$ & $42,3 \mathrm{a}$ & $37,7 \mathrm{a}$ & $41,7 \mathrm{a}$ & 33,7 a & $\mathrm{ns}$ & $30-200$ \\
\hline $\mathrm{Zn}\left(\mathrm{mg} \mathrm{kg}^{-1}\right)$ & $21,6 \mathrm{a}$ & $20,2 \mathrm{a}$ & $21,2 \mathrm{a}$ & $19,0 \mathrm{a}$ & ns & $21,6 \mathrm{a}$ & $22,0 \mathrm{a}$ & $20,3 \mathrm{a}$ & $18,3 \mathrm{a}$ & $\mathrm{ns}$ & $15-50$ \\
\hline $\mathrm{Cd}\left(\mathrm{mg} \mathrm{kg}^{-1}\right)$ & $0,4 \mathrm{a}$ & $0,0 \mathrm{a}$ & $0,0 \mathrm{a}$ & $0,0 \mathrm{a}$ & $\mathrm{ns}$ & $0,2 \mathrm{a}$ & $0,0 \mathrm{a}$ & $0,4 \mathrm{a}$ & $0,2 \mathrm{a}$ & $\mathrm{ns}$ & $<1,0$ \\
\hline $\mathrm{Pb}\left(\mathrm{mg} \mathrm{kg}^{-1}\right)$ & $0,0 \mathrm{a}$ & $0,4 \mathrm{a}$ & $0,7 \mathrm{a}$ & $0,2 \mathrm{a}$ & $\mathrm{ns}$ & $1,1 \mathrm{a}$ & $1,5 \mathrm{a}$ & $1,9 \mathrm{a}$ & $0,0 \mathrm{a}$ & $\mathrm{ns}$ & $<0,8$ \\
\hline $\mathrm{Ni}\left(\mathrm{mg} \mathrm{kg}^{-1}\right)$ & $0,6 \mathrm{a}$ & $0,1 \mathrm{a}$ & $0,4 \mathrm{a}$ & $0,4 \mathrm{a}$ & $\mathrm{ns}$ & $0,4 \mathrm{a}$ & $0,2 \mathrm{a}$ & $0,4 \mathrm{a}$ & $0,4 \mathrm{a}$ & $\mathrm{ns}$ & $<0,5$ \\
\hline $\mathrm{Cr}\left(\mathrm{mg} \mathrm{kg}^{-1}\right)$ & $0,2 \mathrm{a}$ & $0,0 \mathrm{a}$ & $0,5 \mathrm{a}$ & $0,2 \mathrm{a}$ & $\mathrm{ns}$ & $0,7 \mathrm{a}$ & $0,2 \mathrm{a}$ & $0,0 \mathrm{a}$ & $0,0 \mathrm{a}$ & $\mathrm{ns}$ & $<0,1$ \\
\hline
\end{tabular}

\footnotetext{
(1) Médias seguidas da mesma letra na linha não diferem entre si pelo teste de Tukey a 5 \%, dentro de cada forma de aplicação.
} (2) Coeficiente de determinação $\left(\mathrm{R}^{2}\right)$ e significância da regressão, modelo linear, sendo ns: não-significativo; *, ** e *** significativo pelo teste F a 5, 1 e $0,1 \%$, respectivamente. (3) Teores adequados para a pupunheira segundo Bovi \& Cantarella (1996), Deenik et al. (2000), Ares et al. (2002) e Schroth et al. (2002). ${ }^{(4)} \mathrm{T} 1=0$, T2 = 7,7, T3 = 15,4 e T4 = 30,8 Mg ha ${ }^{-1}$ de lodo de esgoto

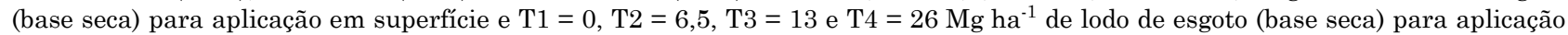
incorporada. 


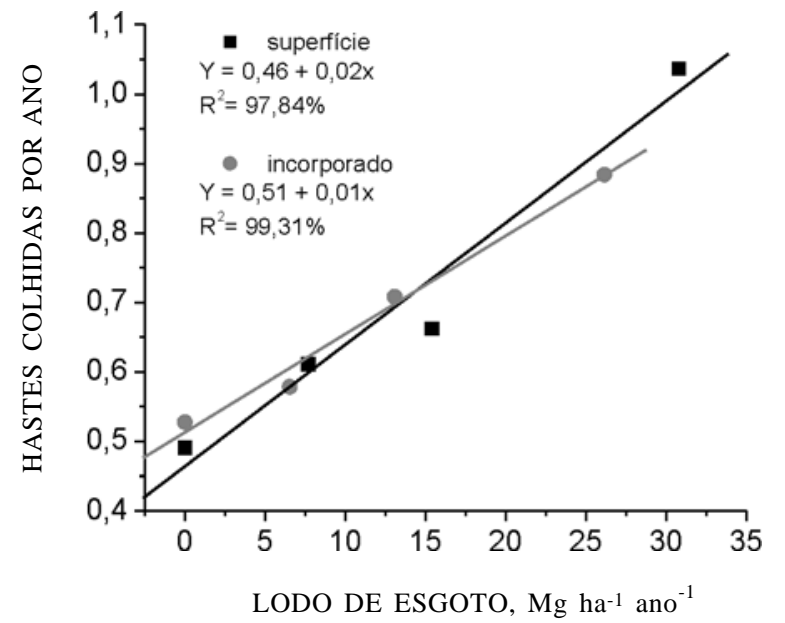

Figura 1. Número médio de hastes colhidas por ano de acordo com as doses de lodo de esgoto aplicadas anualmente, em superfície ou incorporadas, durante a fase de manutenção da cultura da pupunheira.

colhida 1,0 haste, por ano, em cada planta. Isso significa que na dose máxima de lodo foi realizada uma colheita a cada 12 meses, ao passo que na ausência de lodo colheu-se uma haste a cada dois anos. Deve ser mencionado que o número anual de hastes colhidas por planta, obtido com base na média das parcelas, confere maior validade aos resultados da produção alcançada por área, uma vez que inclui também as folhas $(15,81 \%)$, as plantas sem perfilhamento $(13,10 \%)$ e as plantas pouco desenvolvidas (8,04\%).

Para a variável número médio de hastes colhidas por ano em cada planta, o teste de Tukey não detectou efeito significativo na forma de aplicação do lodo, exceto para a maior dose. Nesse tratamento, o número médio de hastes colhidas quando o lodo de esgoto foi aplicado em superfície foi superior $(\mathrm{P}<0,05)$ ao da aplicação sob a forma incorporada. Infere-se que a abertura de valas para incorporação do lodo causou algum dano às raízes, com reflexos na parte aérea das plantas, especialmente nessa dose, em que as valas tiveram maior largura, a fim de comportar a quantidade de lodo (129 Mg ha-1 ano-1 de lodo de esgoto fresco, com $79,7 \%$ de umidade). Vários autores demonstraram que o sistema radicular da pupunheira é bastante superficial, com cerca de 70 a $80 \%$ das raízes responsáveis pela absorção de água e nutriente concentradas nos primeiros $20 \mathrm{~cm}$ de solo (Vandermeer, 1977; Ferreira et al., 1980; Bassoi et al., 1999; Bovi et al., 1999; Vega et al., 2005).

Embora haja superioridade do número de hastes colhidas por planta nas doses mais elevadas de lodo, deve-se ponderar que a produção de palmito é dada por sua massa e não pelo número de hastes. $\mathrm{O}$ peso médio das hastes brutas, após o corte de limbos e pecíolos foliares, variou de 3,4 a 4,0 kg haste ${ }^{-1}$, com rendimento médio de 0,24 a $0,29 \mathrm{~kg}$ de palmito e entre 0,20 e $0,24 \mathrm{~kg}$ de resíduo basal por haste, sem diferenças significativas entre formas de aplicação. No entanto, para se ter uma visão realista da massa média do palmito e do resíduo basal de acordo com as doses de lodo de esgoto, foi considerada a média de todas as colheitas realizadas até novembro de 2004 (40 meses após o início do experimento). Isso porque a colheita de palmito em pupunheira é escalonada e feita de acordo com o desenvolvimento da haste. Conforme relatada por vários autores, a produção de palmito em pupunheiras deve ser avaliada ao longo de um período e envolver não só hastes principais (planta-mãe), mas também seus perfilhos (Villachica, 1996; Mora-Urpi et al., 1997; Bovi, 1998; Ares et al., 2002; Flori et al., 2004). Quanto maior esse período, mais correta será a estimativa da produção quando transformada em quilos ou toneladas por hectare. No presente experimento, a produção foi avaliada no período de 24 meses, o que totalizou de 8 a 12 colheitas efetuadas nas mesmas parcelas.

A produção anual de resíduo basal variou de 0,823 a $1,386 \mathrm{Mg} \mathrm{ha}^{-1} \mathrm{ano}^{-1}$. Não foram observadas diferenças significativas pelo teste $\mathrm{F}$ a $5 \%$ entre as duas formas de aplicação (superfície ou incorporada). Da mesma maneira que para o número de hastes colhidas por planta, houve efeito linear positivo da produção de resíduo basal considerando as doses crescentes de lodo de esgoto anualmente aplicadas no cultivo da pupunheira (Figura 2).

Efeito linear positivo considerando as doses de lodo de esgoto também foi detectado quando da avaliação da produção de palmito propriamente dito (Figura 3). A produção anual dessa porção nobre variou de 0,816 a $1,651 \mathrm{Mg} \mathrm{ha}^{-1} \mathrm{ano}^{-1}$, sem diferenças significativas entre formas de aplicação para todas as doses. De modo geral, e considerando a soma das variáveis

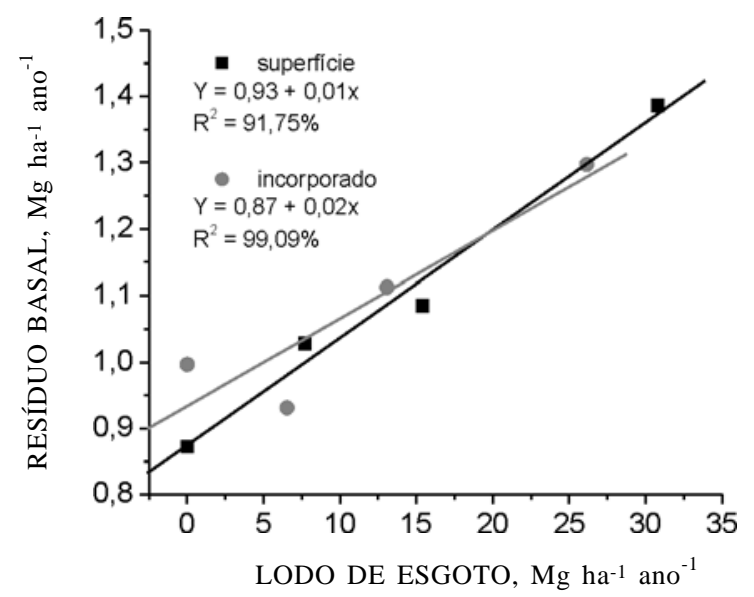

Figura 2. Produção anual de resíduo basal (palmito caulinar) de acordo com as doses de lodo de esgoto aplicadas anualmente, em superfície ou incorporadas, durante a fase de manutenção da cultura da pupunheira. 
resíduo basal e palmito propriamente dito, pode ser concluído que não houve diferença entre as formas de aplicação do lodo de esgoto quando da avaliação da produção total.

Análises químicas do produto colhido em duas épocas e em plantas submetidas às diferentes doses de lodo mostraram que houve variação nos teores de nutrientes e metais pesados no palmito (Quadro 6), mas, de forma geral, observou-se que os teores de elementos potencialmente tóxicos da porção comestível estavam dentro dos limites de tolerância permitidos pela legislação vigente (ABIA, 2003), exceto pelo metal pesado cromo. Para esse metal pesado o limite de tolerância é de 1,0 mg kg-1 em base seca (ABIA, 2003; Viana et al., 1997), enquanto os valores obtidos no presente experimento estiveram entre $1,02 \mathrm{e}$ $4,34 \mathrm{mg} \mathrm{kg}^{-1}$. Como o cromo foi encontrado em teores acima do limite referencial, mesmo na testemunha (dose 0 de lodo de esgoto), conclui-se que o assunto necessita de estudos mais aprofundados para dissipar dúvidas a esse respeito.

É interessante notar que tanto para o resíduo basal quanto para o palmito propriamente dito não foi obtido um ponto de máximo, com decréscimo a partir dele. Isso indica que, do ponto de vista de produtividade, doses maiores que as deste estudo poderiam ainda ser utilizadas. No entanto, deve-se ter cautela ao avaliar esses resultados, visto que doses elevadas de lodo de esgoto podem causar danos ao ambiente, como lixiviação de nitrato ao longo do perfil do solo (Burton et al., 1990; Oliveira, 1995; Vieira \& Cardoso, 2003; Molina, 2004), atingindo o lençol freático, além da possibilidade de acúmulo de metais pesados (Higgins, 1984; Bertoncini \& Mattiazzo, 1999; Berton, 2000; Keller et al., 2002; Molina, 2004). Estudo do acúmulo de metais pesados ao longo do perfil do solo foi efetuado em duas datas (12 e 40 meses após o plantio) e será apresentado em outra oportunidade.

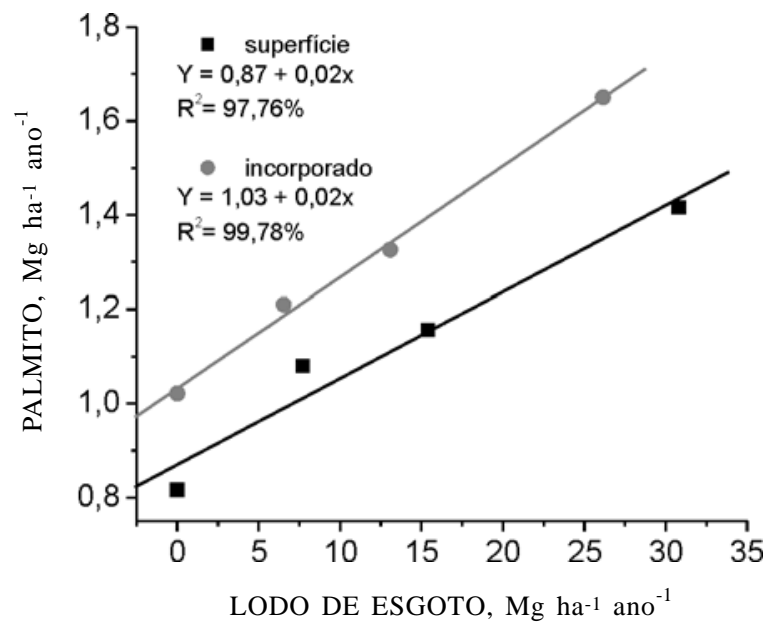

Figura 3. Produção anual de palmito considerando as doses de lodo de esgoto aplicadas anualmente, em superfície ou incorporadas, durante a fase de manutenção da cultura da pupunheira.

Quadro 6. Teores foliares médios de macro e micronutrientes e metais pesados em palmito de pupunheiras 15 meses após a aplicação de lodo de esgoto no sulco do plantio (fase de implantação) e 75 dias após a última aplicação de lodo de esgoto em superfície (fase de manutenção) ${ }^{(1)}$

\begin{tabular}{|c|c|c|c|c|c|c|c|c|c|c|}
\hline \multirow{2}{*}{ Elemento } & \multicolumn{5}{|c|}{ Palmito na fase de implantação } & \multicolumn{5}{|c|}{ Palmito na fase de manutenção } \\
\hline & $\mathbf{T} 1^{(3)}$ & $\mathbf{T} 2$ & T3 & $\mathbf{T} 4$ & $\mathbf{R}^{2(2)}$ & $\mathbf{T} 1^{(3)}$ & $\mathrm{T} 2$ & T3 & T4 & $\mathbf{R}^{2(2)}$ \\
\hline $\mathrm{N}\left(\mathrm{g} \mathrm{kg}^{-1}\right)$ & $50,1 \mathrm{a}$ & 50,6 a & $46,0 \mathrm{a}$ & 50,4 a & $\mathrm{ns}$ & $50,1 \mathrm{a}$ & $51,1 \mathrm{a}$ & 47,6 a & $51,7 \mathrm{a}$ & $\mathrm{ns}$ \\
\hline $\mathrm{P}\left(\mathrm{g} \mathrm{kg}^{-1}\right)$ & $8,7 \mathrm{a}$ & $7,4 \mathrm{a}$ & $8,5 \mathrm{a}$ & $8,2 \mathrm{a}$ & $\mathrm{ns}$ & $10,1 \mathrm{a}$ & $10,2 \mathrm{a}$ & $9,4 \mathrm{a}$ & $10,4 \mathrm{a}$ & $\mathrm{ns}$ \\
\hline $\mathrm{K}\left(\mathrm{g} \mathrm{kg}^{-1}\right)$ & 33,9 a & $24,4 \mathrm{ab}$ & $21,5 \mathrm{ab}$ & $16,4 \mathrm{~b}$ & $-0,69 * *$ & 37,9 a & $32,4 \mathrm{a}$ & $30,1 \mathrm{a}$ & $28,3 \mathrm{a}$ & $-0,53^{*}$ \\
\hline $\mathrm{Ca}\left(\mathrm{g} \mathrm{kg}^{-1}\right)$ & $3,4 \mathrm{a}$ & $3,3 \mathrm{a}$ & $3,4 \mathrm{a}$ & $2,7 \mathrm{a}$ & $\mathrm{ns}$ & $4,5 \mathrm{a}$ & $4,2 \mathrm{a}$ & $4,3 \mathrm{a}$ & $4,8 \mathrm{a}$ & $\mathrm{ns}$ \\
\hline $\mathrm{Mg}\left(\mathrm{g} \mathrm{kg}^{-1}\right)$ & $3,8 \mathrm{a}$ & $3,7 \mathrm{a}$ & $4,4 \mathrm{a}$ & $3,6 \mathrm{a}$ & $\mathrm{ns}$ & $6,9 \mathrm{a}$ & $6,4 \mathrm{a}$ & $6,4 \mathrm{a}$ & $6,6 \mathrm{a}$ & $\mathrm{ns}$ \\
\hline $\mathrm{S}\left(\mathrm{g} \mathrm{kg}^{-1}\right)$ & $3,6 \mathrm{a}$ & $3,7 \mathrm{a}$ & $4,1 \mathrm{a}$ & $3,9 \mathrm{a}$ & $\mathrm{ns}$ & $4,8 \mathrm{a}$ & $4,4 \mathrm{a}$ & $4,3 \mathrm{a}$ & $4,2 \mathrm{a}$ & $\mathrm{ns}$ \\
\hline $\mathrm{B}\left(\mathrm{mg} \mathrm{kg}^{-1}\right)$ & $25,7 \mathrm{a}$ & $26,2 \mathrm{a}$ & $26,7 \mathrm{a}$ & $26,4 \mathrm{a}$ & $\mathrm{ns}$ & $29,0 \mathrm{a}$ & $27,7 \mathrm{a}$ & $28,0 \mathrm{a}$ & $28,4 \mathrm{a}$ & $\mathrm{ns}$ \\
\hline $\mathrm{Cu}\left(\mathrm{mg} \mathrm{kg}^{-1}\right)$ & $15,0 \mathrm{a}$ & $12,7 \mathrm{ab}$ & $11,0 \mathrm{ab}$ & $8,8 b$ & $-0,68 * *$ & $21,5 \mathrm{a}$ & $22,0 \mathrm{a}$ & $20,3 \mathrm{a}$ & $18,7 \mathrm{a}$ & $-0,57^{*}$ \\
\hline $\mathrm{Fe}\left(\mathrm{mg} \mathrm{kg}^{-1}\right)$ & $45,5 \mathrm{a}$ & $10,5 \mathrm{a}$ & $32,8 \mathrm{a}$ & $22,7 \mathrm{a}$ & $\mathrm{ns}$ & $82,0 \mathrm{a}$ & $92,7 \mathrm{a}$ & $62,7 \mathrm{a}$ & $76,0 \mathrm{a}$ & $\mathrm{ns}$ \\
\hline $\operatorname{Mn}\left(\mathrm{mg} \mathrm{kg}^{-1}\right)$ & $32,2 \mathrm{a}$ & 32,6 a & $44,2 \mathrm{a}$ & $38,2 \mathrm{a}$ & $\mathrm{ns}$ & $61,7 \mathrm{a}$ & 56,7 a & 59,5 a & $63,2 \mathrm{a}$ & $\mathrm{ns}$ \\
\hline $\mathrm{Zn}\left(\mathrm{mg} \mathrm{kg}^{-1}\right)$ & 68,9 a & $67,6 \mathrm{a}$ & 79,7 a & $61,7 \mathrm{a}$ & $\mathrm{ns}$ & $93,0 \mathrm{a}$ & 89,5 a & $85,5 \mathrm{a}$ & $91,5 \mathrm{a}$ & $\mathrm{ns}$ \\
\hline $\mathrm{Cd}\left(\mathrm{mg} \mathrm{kg}^{-1}\right)$ & $0,6 \mathrm{a}$ & $0,5 \mathrm{a}$ & $0,7 \mathrm{a}$ & $0,4 \mathrm{a}$ & $\mathrm{ns}$ & $0,7 \mathrm{a}$ & $1,0 \mathrm{a}$ & $0,9 \mathrm{a}$ & $0,7 \mathrm{a}$ & $\mathrm{ns}$ \\
\hline $\mathrm{Pb}\left(\mathrm{mg} \mathrm{kg}^{-1}\right)$ & $1,5 \mathrm{a}$ & $4,8 \mathrm{a}$ & $3,9 \mathrm{a}$ & $4,2 \mathrm{a}$ & $\mathrm{ns}$ & $2,1 \mathrm{a}$ & $5,4 \mathrm{ab}$ & $9,6 \mathrm{~b}$ & $9,8 b$ & $0,69^{* *}$ \\
\hline $\mathrm{Ni}\left(\mathrm{mg} \mathrm{kg}^{-1}\right)$ & $1,9 \mathrm{a}$ & $1,4 \mathrm{a}$ & $3,4 \mathrm{a}$ & $2,4 \mathrm{a}$ & $\mathrm{ns}$ & $3,2 \mathrm{a}$ & $2,5 \mathrm{a}$ & $4,3 \mathrm{a}$ & $4,9 \mathrm{a}$ & $\mathrm{ns}$ \\
\hline $\mathrm{Cr}\left(\mathrm{mg} \mathrm{kg}^{-1}\right)$ & $2,9 \mathrm{a}$ & $1,8 \mathrm{a}$ & $2,0 \mathrm{a}$ & $3,0 \mathrm{a}$ & $\mathrm{ns}$ & $4,0 \mathrm{a}$ & $1,9 \mathrm{a}$ & $1,0 \mathrm{a}$ & $2,5 \mathrm{a}$ & $\mathrm{ns}$ \\
\hline
\end{tabular}

(1) Médias seguidas da mesma letra na linha não diferem entre si pelo teste de Tukey a $5 \%$, dentro de cada fase. ${ }^{(2)}$ Coeficiente de determinação $\left(R^{2}\right)$ e significância da regressão, modelo linear, sendo ns não significativo; * ${ }^{* *}$ significativo pelo teste $\mathrm{F}$ a 5 e $1 \%$, respectivamente. ${ }^{(3)} \mathrm{T} 1=0, \mathrm{~T} 2=7,7, \mathrm{~T} 3=15,4 \mathrm{e} \mathrm{T} 4=30,8 \mathrm{Mg} \mathrm{ha}^{-1}$ de lodo de esgoto (base seca) para a aplicação em superfície e $\mathrm{T} 1=0, \mathrm{~T} 2=6,5, \mathrm{~T} 3=13$ e $\mathrm{T} 4=26 \mathrm{Mg} \mathrm{ha}^{-1}$ de lodo de esgoto (base seca) para a aplicação no sulco de plantio. 
Deve-se alertar também para as dificuldades de aplicação de lodo de esgoto na cultura já formada. $\mathrm{O}$ espaçamento adensado $(2 \times 1 \mathrm{~m})$, recomendado para o cultivo da pupunheira, impede a entrada de maquinário adequado para agilizar e tornar mais segura a aplicação periódica de lodo, mesmo em superfície. Espaçamentos maiores que esse aumentam os tratos culturais, visto que há forte competição com plantas daninhas, o que eleva também o custo de manutenção. Deve-se ainda atentar para o fato de que a dose de lodo equivalente a $200 \mathrm{~kg} \mathrm{ha}$ 1 ano $^{-1}$ de N (uma vez a NC) é adequada para a fase de implantação, já que na realidade atual do cultivo não se realiza a adubação orgânica, devido ao seu elevado custo. No entanto, essa dose não atende plenamente às necessidades da planta na fase de manutenção do cultivo. Assim, para produção plena e competitividade no agronegócio do palmito, haveria necessidade de complementá-la com adubação química.

\section{CONCLUSÕES}

1. O uso de lodo de esgoto durante a implantação do cultivo da pupunheira afetou positivamente a precocidade de colheita de palmito, com efeito linear significativo e positivo das doses empregadas.

2. A aplicação anual de lodo de esgoto promoveu aumento da produção de palmito e maior periodicidade de colheita, com acréscimos proporcionais às doses utilizadas.

3. Não houve diferenças significativas entre as duas formas de aplicação de lodo de esgoto testadas durante a fase de manutenção da cultura. Como a aplicação em superfície é mais fácil e rápida que a incorporada, ela pode ser recomendada quando do uso de lodo de esgoto no cultivo da pupunheira.

\section{AGRADECIMENTOS}

À SABESP, pelo financiamento parcial do projeto de pesquisa, e à FundAg, pela concessão de bolsa para os pós-graduandos Fernando, Carlos e Matheus.

\section{LITERATURA CITADA}

ABREU, M.F. Extração e determinação simultânea por emissão em plasma de nutrientes e elementos tóxicos em amostras de interesse agronômico. Campinas, Universidade Estadual de Campinas, 1997. 135p. (Tese de Doutorado)

ABREU, C.A.; ABREU, M.F. \& ANDRADE, J.C. Determinação de cobre, ferro, manganês, zinco, cádmio, cromo, níquel e chumbo em solos usando a solução de DTPA em pH 7,3. In: RAIJ, B. van; ANDRADE, J.C.; CANTARELLA, H. \& QUAGGIO, J.A., eds. Análise química para avaliação da fertilidade de solos tropicais. Campinas, Instituto Agronômico, 2001. 285p.
AGRIANUAL 2005: anuário da agricultura brasileira. São Paulo, FNP Consultoria \& Comércio, 2005. 521p.

ANJOS, A.R.M. \& MATTIAZZO, M.E. Metais pesados em plantas de milho cultivadas em Latossolo repetidamente tratados com biossólido. Sci. Agric., 57:769-776, 2000.

ARES, A.; FALCÃO, N.; YUYAMA, K.; YOST, R.S. \& CLEMENT, C.R. Response to fertilization and nutrient deficiency diagnostics in peach palm in Central Amazonia. Nutr. Cycl. Agroec., 66:221-232, 2003.

ASSOCIAÇÃO BRASILEIRA DAS INDÚSTRIAS DA ALIMENTAÇ̃̃O - ABIA. Compêndio da legislação de alimentos. Atos do Ministério da Saúde e ANVISA. Revisão $n^{\circ}$ 9, São Paulo, 2003. Disponível em: <www.abia.org.br/ vst/publ_txt2.htm> Acesso em: 10 set. 2006.

BASSOI, L.H.; FLORI, J.E.; ALENCAR, C.M.; SILVA, J.A.M. \& RAMOS, C.M.C. Distribuição espacial do sistema radicular da pupunheira em solos irrigados no Vale do São Francisco. Eng. Agric., 19:163-176, 1999.

BATAGLIA, O. C.; FURLANI, A. M. C.; TEIXEIRA, J.P. \& GALLO, J.R. Métodos de análise química de plantas. Campinas, Instituto Agronômico de Campinas, 1983b. 48p. (Boletim Técnico, 78)

BATAGLIA, O.C.; BERTON, RS.; CAMARGO, O.A. \& VALADARES, I.M.A.S. Resíduos orgânicos como fontes de nitrogênio para capim-braquiária. R. Bras. Ci. Solo, 7:277-284, 1983a.

BERTON, R.S. Riscos de contaminação do agroecossistema com metais pesados. In: BETTIOL, W. \& CAMARGO, O.A., eds. Impacto ambiental do uso agrícola do lodo de esgoto. Jaguariúna, Embrapa Meio Ambiente, 2000. p.259268.

BERTON, R.S. \& CAMARGO, O.A. Uso agrícola do lodo de esgoto, da matéria orgânica do lixo urbano e de resíduos industriais. Agronômico, 56:5-8, 2004.

BERTON, R.S.; CAMARGO, O.A. \& VALADARES, J.M.AS. Absorção de nutrientes pelo milho em resposta à adição de lodo de esgoto a cinco solos paulistas. R. Bras. Ci. Solo, 13:187-192, 1989

BERTONCINI, E.I. \& MATTIAZZO, M.E. Lixiviação de metais pesados em solos tratados com lodos de esgoto. R. Bras. Ci. Solo, 23:737-744, 1999.

BOVI, M.L.A. Palmito pupunha: informações básicas para cultivo. Campinas, Instituto Agronômico, 1998. 50p. (Boletim Técnico, 173)

BOVI, M.L.A. \& CANTARELLA, H. Pupunha para extração de palmito. In: RAIJ, B. van; CANTARELLA, H.; QUAGGIO, J.A. \& FURLANI, A.M.C., eds. Recomendações de adubação para algumas culturas do estado de São Paulo. Campinas, Instituto Agronômico, 1996. p.240-242. (Boletim Técnico, 100)

BOVI, M.L.A.; GODOY JR., G. \& SPIERING, S.H. Respostas de crescimento da pupunheira à adubação NPK. Sci. Agric., 59:161-166, 2002

BOVI, M.L.A.; GODOY, JR.G. \& SPIERING, S.H. Adubação de implantação afetando perfilhamento em pupunheira. In: REUNIÃO BRASILEIRA DE MANEJO E CONSERVAÇÃO DO SOLO E DA ÁGUA, 13., 2000, Ilhéus. Anais eletrônicos. Ilhéus, CEPLAC, 2000. CD-ROM. 
BOVI, M.L.A.; SPIERING, S.H. \& BARBOSA, A.M.M. Densidade radicular de progênies de pupunheira em função de adubação NPK. Hortic. Bras., 17:186-193, 1999.

BURTON, J.A.; HART JUNIOR, J.B. \& URIE, D.H. Nitrification in sludge-amended Michigan forest soils. J. Environ. Qual., 19:600-616, 1990.

CLEMENT, C.R. \& BOVI, M.L.A. Padronização de medidas de crescimento e produção em experimentos com pupunha para palmito. Act Amaz., 30:349-362, 2000.

COMPANHIA DE TECNOLOGIA DE SANEAMENTO AMBIENTAL - CETESB. Relatório de estabelecimento de valores orientadores para solos e água subterrâneas do Estado de São Paulo. São Paulo, 2001. 232p.

DEENIK, J.; ARES, A. \& YOST, R.S. Fertilization response and nutrient diagnosis in peach palm (Bactris gasipaes) a review. Nutr. Cycl. Agroec., 56:195-207, 2000.

EMPRESA BRASILEIRA DE PESQUISA AGROPECÁRIA EMBRAPA. Centro Nacional de Pesquisa em Solos. Sistema Brasileiro de Classificação de Solos. Brasília , 1999. $412 \mathrm{p}$

FERREIRA, S.A.; CLEMENT, C.R. \& RANZANI, G. Contribuição para o conhecimento do sistema radicular da pupunheira (Bactris gasipaes H.B.K. - Guilielma gasipaes (H.B.K.) Bailey). Acta Amaz., 10:245-249, 1980.

FLORI, J.E.; RESENDE, G.M. \& DRUMOND, M.A. Rendimento em função da densidade de plantio, diâmetro de corte e manejo dos perfilhos no Vale de São Francisco. Ci. Agrotéc., 28:70-74, 2004.

GUEDES, M.C.; ANDRADE, C.A.; POGGIANI, F. \& MATTIAZZO, M.E. Propriedades químicas do solo e nutrição do eucalipto em função da aplicação de lodo de esgoto. R. Bras. Ci. Solo, 30:267-280, 2006.

HERRERA, W. Fertilización del pejibaye para palmito. Pejibaye, B. Inf., 1:5-10, 1989.

HIGGINS, J.A. Land application of sewage sludge with regard to cropping system and pollution potential. J. Environ. Qual., 13:441-448, 1984.

JORGE, J.A. \& BOVI, M.L.A. Influência das propriedades físicas e químicas do solo no crescimento da palmeira pupunha. In: CONGRESSO BRASILEIRO DE FRUTICULTURA, 13.; Salvador, 1994. Resumos expandidos. Salvador, Sociedade Brasileira de Fruticultura, 1994. p.1145-1146.

KELLER, C.; Mc GRATH, C. \& DUNHAM, C. Trace metal leaching through a soil grassland system and sewage sludge application. J. Environ. Qual., 31:1550-1560, 2002.

LOPES, J.C.; RIBEIRO, L.G.; ARAÚJO, M.G. \& BERALDO, M.R.B.S. Produção de alface com doses de lodo de esgoto. Hortic. Bras., 23:143-147, 2005.

MANCIOT, E.; OLLAGNIER, M. \& OCHS, R. Mineral nutrition and fertilization of the coconut around the world. Oleagineux, 35:23-27, 1980.

MARTINS, D.R.; CAMARGO, O.A. \& BATAGLIA, O.C. Qualidade do grão e da bebida em cafeeiros tratados com lodo de esgoto. Bragantia, 64:115-126, 2005.
MELO, W.J. \& MARQUES, M.O. Potencial do lodo de esgoto como fonte de nutrientes para as plantas. In: BETTIOL, W. \& CAMARGO, O.A., eds. Impacto ambiental do uso agrícola do lodo de esgoto. Jaguariúna, Embrapa Meio Ambiente, 2000. p.109-141.

MOLINA, E.; ALVARADO, A.; SMYTH, T.J.; BONICHE, J.; ALPIZAR, D. \& OSMOND, D. Respuestas del pejibaye para palmito (Bactris gasipaes) al nitrógeno en andisoles de Costa Rica. Agron. Costarricence, 26:31-42, 2002.

MOLINA, M.V. Nitrogênio e metais pesados em latossolo e eucalipto cinqüenta e cinco meses após a aplicação de biossólido. Piracicaba, Escola Superior de Agricultura "Luiz de Queiroz", 2004. 66p (Tese de Mestrado)

MORA-URPI, J.; WEBER, J.C. \& CLEMENT, C.R. Peach palm (Bactris gasipaes Kunth), promoting the conservation and use of underutilized and neglected crops. 20. Rome, Institute of Plant Genetics and Crop Plant Research, 1997. $83 p$.

NASCIMENTO, C.W.A.; BARROS, D.A.S.; MELO, E.E.C. \& OLIVEIRA, A.B. Alterações químicas em solos e crescimento de milho e feijoeiro após aplicação de lodo de esgoto. R. Bras. Ci. Solo, 28:385-392, 2004.

NASCIMENTO, J.T.; OLIVEIRA, A.P.; SOUZA, A.P.; SILVA, I.F. \& ALVES, A.U. Rendimento de palmito de pupunheira em função da aplicação de esterco bovino e adubação química. Hortic. Bras., 23:19-21, 2005.

OLIVEIRA, A.P.; CANDEIA B.L.; BENVINDA, J.M.S; BARBOSA, L.J.; SILVA J.V. \& ALVES, A.U. Crescimento da pupunheira em função de fontes e doses de matéria orgânica. Hortic. Bras., 19(Suplemento), 2001. CD-ROM.

OLIVEIRA, F.C. Metais pesados e formas nitrogenadas em solos tratados com lodo de esgoto. Piracicaba, Escola Superior de Agricultura "Luiz de Queiroz", 1995. 90p. (Tese de Mestrado)

OLIVEIRA, F.C. \& MATTIAZZO, M.E. Metais pesados em latossolo tratado com lodo de esgoto e em plantas de canade-açúcar. Sci.Agric., 58:581-593, 2001.

OLIVEIRA, F.C.; MARQUES, M.O.; BELLINGIERI, P.A. \& PERECIN, D. Lodo de esgoto como fonte de macronutrientes para a cultura do sorgo granífero. Sci. Agric., 52:360-367, 1995.

OLLAGNIER, M.; OCHS, R. \& MARTIN, G. Adubação do dendezeiro no mundo. Fertilité, 36:1-67, 1970.

RAIJ, B. van \& QUAGGIO, J.A. Determinação de fósforo, cálcio, magnésio e potássio extraídos com resina trocadora de íons. In: RAIJ, B. van; ANDRADE, J.C.; CANTARELLA, H. \& QUAGGIO, J.A., eds. Análise química para avaliação da fertilidade de solos tropicais. Campinas, Instituto Agronômico de Campinas, 2001. p.189-199.

RAIJ, B. van. Fertilidade do solo e adubação. Piracicaba, Potafos, 1991. 343p.

RAMOS, A. Análise do desenvolvimento vegetativo e produtividade da palmeira pupunha (Bactris gasipaes Kunth) sob níveis de irrigação e adubação nitrogenada. Piracicaba, Escola Superior de Agricultura "Luiz de Queiroz, 2002. 113p. (Tese de Doutorado) 
RAMOS, A.; BOVI, M.L.A.; FOLEGATTI, M.V. \& DIOTTO, A. Efeitos da fertirrigação sobre a produção de palmito de pupunheira. Hortic. Bras., 22:734-739, 2004.

SCAVRONI, J.; BOARO, C.S.F.; MARQUES, M.O.M. \& FERREIRA, L.C. Yield and composition of the essential oil of Mentha piperita L. (Lamiceae) grown with biosolid. Braz. J. Plant Physiol., 17:345-352, 2005.

SCHROTH, G.; ELIAS, M.E.A.; MACÊDO, J.L.V.; MOTA, M.S.S. \& LIEBEREI, R. Mineral nutrition of peach palm (Bactris gasipaes) in Amazonian agroforestry and recommendation for foliar analysis. Eur. J. Agron., 17:81$92,2002$.

SECRETARIA, M.I. \& MARAVILLA, J.N. Response of hybrid coconut palms to application of manures and fertilizers from field-planting to full-bearing stage. Plant. Rech. Dévelop., 4:126-138, 1997.

SERRA-WITTLING, C.; HOUOT, S. \& BARRIUSO, E. Modification of soil water retention and biological properties by municipal solid waste compost. Comp. Sci. Utiliz., 4:44-52, 1996.

SETZER, J. Atlas climático e ecológico do Estado de São Paulo. São Paulo, 1966. 61p

SILVA, C.A.; RANGEL, O.J.P.; DYNIA, J.F.; BETTIOL, W. \& MANZATTO, C.V. Disponibilidade de metais pesados para milho cultivado em Latossolo sucessivamente tratado com lodos de esgoto. R. Bras. Ci. Solo, 30:353-364, 2006.

SILVA, F.C.; BOARETTO, A.E.; BERTON, R. S.; ZOTELLI, H.B.; PEIXE, C.A.\& BERNARDES, E.M. Efeito do lodo de esgoto na fertilidade de um Argissolo VermelhoAmarelo cultivado com cana-de-açúcar. Pesq. Agropec. Bras., 36:831-840, 2001.

SNEDECOR, G.W. \& COCHRAN, W.G. Statistical methods. Ames, Iowa State University Press, 1989. 507p.

STEEL, R.G.D. \& TORRIE, J.H. Principles and procedures of statistics: a biometrical approach. New York, McGrawHill, 1980. 632p.

TAMPUBOLON, F.H.; DANIEL, C. \& OCHS, R. Réponses du palmier à huile aux fumures azotées et phosphorées à Sumatra. Oléagineux, 45:475-484, 1990.
TRIGUEIRO, R.M. \& GUERRINI, I.A. Uso de biossólido como substrato para produção de mudas de eucalipto. Sci. For., 64:150-162, 2003.

TSUTIYA, M.T. Alternativas de disposição final de biossólidos. In: TSUTIYA, M.T.; CAMPARINI, J.B.; ALEM SOBR ${ }^{\circ}$ P.; HESPANHOL, I.; DE CARVALHO, P.C.T.; MELFI, A.J.; MELO, W.J. \& MARQUES, M.O., eds. Biossólidos na agricultura. São Paulo, SABESP, 2001. p.133-178.

VANDERMEER, J. Observations on the root system of the pejibaye palm (Bactris gasipaes H.B.K.) in Costa Rica. Turrialba, 27:237-242, 1977.

VEGA, F.V.A. Uso de lodo de esgoto na implantação da cultura da pupunheira (Bactris gasipaes Kunth). Campinas, Instituto Agronômico de Campinas, 2003. 129p. (Tese de Mestrado)

VEGA, F.V.A.; BOVI, M.L.A.; GODOY JR., G. \& BERTON R.S. Lodo de esgoto e sistema radicular da pupunheira. R. Bras. Ci. Solo, 29:259-268, 2005.

VIANA, A.G.; MANTOVANI, D..M.B.; VICENTE, E.; OLIVEIRA, J.J. \& PANIWAKI, M.H. Contaminantes inorgânicos em alimentos: Conceitos e legislações. In: SEMINÁRIO SOBRE CONTAMINANTES EM ALIMENTOS, 1., Campinas, 1997. Anais.Campinas, Instituto de Tecnologia de Alimentos, 1:45-53, 1997.

VIEIRA, R.F. \& CARDOSO, A.C. Variações nos teores de nitrogênio mineral em solo suplementado com lodo de esgoto. Pesq. Agropec. Bras., 38:867-874, 2003.

VIEIRA. R.F.; TANAKA, R.T.; TSAI, S.M.; PÉREZ, D.V. \& SILVA, C.M.M.S. Disponibilidade de nutrientes no solo, qualidade de grãos e produtividade da soja em solo adubado com lodo de esgoto. Pesq. Agropec. Bras., 40:919-926, 2005.

VILLACHICA, H.L. Cultivo de pijuayo (Bactris gasipaes Kunth) para palmito en la amazonia. Tratado de Cooperación Amazónica. Lima - Peru, 1996. 146p.

YUYAMA, K. Sistemas de cultivo para produção de palmito da pupunheira. Hortic. Bras. 15:191-198, 1997. (Suplemento) 